\title{
Are Self-Driving Vehicles Ready to Launch? An Insight into Steering Control in Autonomous Self-Driving Vehicles
}

\author{
Marya Rasib, ${ }^{1,2}$ Muhammad Atif Butt, ${ }^{1,2}$ Shehzad Khalid, ${ }^{3}$ Samia Abid, ${ }^{1,2}$ Faisal Raiz, ${ }^{1,2}$ \\ Sohail Jabbar, ${ }^{4}$ and Kijun Han $\mathbb{D}^{5}$ \\ ${ }^{1}$ Control, Automotive and Robotics Lab, Affiliated Lab of National Centre of Robotics and Automation (NCRA), HEC, \\ Islamabad, Pakistan \\ ${ }^{2}$ Department of Computer Science and Information Technology, Mirpur University of Science and Technology (MUST), \\ Mirpur 10250, AJK, Pakistan \\ ${ }^{3}$ Department of Computer Engineering, Bahria University, Islamabad, Pakistan \\ ${ }^{4}$ Department of Computational Sciences, The University of Faisalabad, Faisalabad, Pakistan \\ ${ }^{5}$ School of Computer Science and Engineering, Kyungpook National University, Daegu, Republic of Korea
}

Correspondence should be addressed to Kijun Han; kjhan@knu.ac.kr

Received 31 October 2020; Revised 12 January 2021; Accepted 19 January 2021; Published 18 February 2021

Academic Editor: Mehmet Cunkas

Copyright (C) 2021 Marya Rasib et al. This is an open access article distributed under the Creative Commons Attribution License, which permits unrestricted use, distribution, and reproduction in any medium, provided the original work is properly cited.

In the last couple of years, academia-industry collaboration has demonstrated rapid advancements in the development of selfdriving vehicles. Since it is evident that self-driving vehicles are going to reshape the traditional transportation systems in near future through enhancement in safe and smart mobility, motion control in self-driving vehicles while performing driving tasks in a dynamic road environment is still a challenging task. In this regard, we present a comprehensive study considering the evolution of steering control methods for self-driving vehicles. Initially, we discussed an insight into the traditional steering systems of the vehicles. To the best of our knowledge, currently, there is no taxonomy available, which elaborates steering control methods for self-driving vehicles. In this paper, we present a novel taxonomy including different steering control methods which are categorized into deterministic and heuristic steering control methods. Concurrently, the abovementioned techniques are critically reviewed elaborating their strengths and limitations. Based on the analysis, key challenges/research gaps in existing steering control methods along with the possible solutions have been briefly discussed to improve the effectiveness of the steering system of self-driving vehicles.

\section{Introduction}

Self-driving technology is under development for the past couple of decades, which has considerable potential to reshape the traditional transportation systems. These developments are increased with the rapid advancements in the sensing and computational technologies considering the potential impact on the perceived societal benefits: according to the recent fact sheet of the world health organization [1-4], 1.35 million people die every year because of the road traffic accidents around the world. Among these, $94 \%$ of the road crashes are ascribed to the negligence of the human drivers, that is, exceeding the speed limit and intoxicating while driving [5-8]. Selfdriving technology is considered as a solution, not only to reduce road collisions but to provide facilely and costeffective commuting services to the passengers as well [9-11]. These efficacies are due to inordinate leisure potentials, that is, efficient fuel consumption, enhanced throughput, and optimal motion planning while commuting through the defined routes.

The society of automotive Engineers (SAE) has presented six autonomy levels referring to self-driving vehicles, ranging from level 0 , no autonomy, to level 5, full autonomy, which has been adopted as a standard for the development of self-driving vehicles [12-15]. Level 0 cars 
are human-driven, having no support of the autonomy system. Level 1 autonomy including driving assistance functions to help human drivers while commuting, that is, cruise control and antilock braking system. These functionalities are enhanced in level 2 autonomy, which involves semiautonomous driving features, that is, lane control while keeping front-end safety measures in view. In level 3 autonomy, an onboard automated driving system can take over all driving controls in case of any uncertain situation. However, the driver must be alert throughout the drive to take control back in case of an undesiring scenario. Level 4 autonomy defines fully autonomous driving functions having a driver behind the wheel; however, the driver still has the option to take control back in case of the least befitting decision by an autopilot, whereas level 5 autonomy includes full self-driving functionalities which are capable of driving from source to destination without any human intervention. These cars are undergoing testing phase in several research centres around the world, and it is projected that these cars will be available in the market by $2030[16,17]$.

A core self-driving technology can be broadly classified into four categorized: (i) sensing, (ii) perception, (iii) planning, and (iv) control [18-21]. Sensing refers to the capability of the autonomous vehicle to collect real-time data from a variety of sensors (i.e., cameras, ultrasonic sonars, LiDARs, and radars) connected with self-driving cars to extract useful information from the environment. The perception module develops the contextual understanding of an environment such as object detection, localization, lane markings, and road signboards based on the information provided by the sensing module. In the next step, the planning module optimizes the information received from the perception module to take decisions in terms of optimal motion planning which leads to the defined goal. Finally, the control module is responsible for the execution of instructions defined by the planning module such as longitudinal (speed, brake) and lateral (steering) motion control.

There has been extensive research on the technical aspects of the abovementioned subjects of self-driving vehicles. To limit the scope of this study, we primarily focus on the control system of self-driving vehicles; in particular, steering control systems of autonomy level 3 and above. An automated steering control system is one of the most crucial elements of autonomous driving which is responsible for safe and optimal motion control in selfdriving vehicles $[22,23]$. Referring to Figure 1 , this study is focused on the latest developments and evolution of the steering control systems for self-driving vehicles indicating the research contributions ranging from 2015 to 2020. To the best of our knowledge, no taxonomy exhibiting the steering control methods has been presented in the existing literature. In this study, we present a novel taxonomy to provide an overview of the evolution in the development of steering control methods in Section 2. Based on the thorough analysis, research challenges have been raised in Section 3. Finally, the article is concluded in Section 4.

\section{Taxonomy}

The steering control system of a self-driving vehicle is one of the most crucial automation challenges due to the mobility constraints: motion velocity, capacity, excessive-speed operations, and the complex interplay with the environment $[24,25]$. In the literature, various methods have been proposed to automate and improve the effectiveness of steering control systems in self-driving vehicles. These methods are categorized into (i) deterministic and (ii) heuristic/hybrid steering control methods [26, 27], as shown in Figure 2.

\subsection{Deterministic}

Definition 1. According to Siddique and Adeli [27], deterministic methods always produce the same output against the given input condition.

The deterministic methods are primarily classic with no randomness; these methods are highly exploitive with a lower capacity for exploration simultaneously [28]. The deterministic mathematical models provide a single solution representing the outcomes of certain "experiment" inputs. Moreover, these methods not only produce the same output from the initial input but also take the same amount of time, memory, and resources every time while executing the corresponding input. Since these methods always produce the same output against the given input, its base machine follows the same set of sequence [29]. Deterministic methods are further divided into two major categories, that is, geometric-based methods and feedback-based methods [24].

2.1.1. Geometric-Based Methods. In the literature, numerous geometric-based methods have been presented to automate the steering control system of self-driving vehicles. These controllers establish a geometric relationship between the current vehicle position and the corresponding reference path to estimate the steering wheel angle [29-32]. Some of the most widely used geometric-based methods are pure pursuit [24], Stanley [33], and vector pursuit [34]. The researchers have made significant contributions in the abovementioned methodologies to improve the effectiveness of the steering control systems of self-driving vehicles, as briefly discussed in the following subsections.

(1) Pure Pursuit. Pure pursuit, a well-known geometric control method, was introduced by Wallace et al. [35] in the mid of 1980 to estimate the steering wheel angle to maintain the lateral stability of the self-driving vehicles. The core concept of these methods is to place a reference point at a certain distance on the path ahead and command the steering system to seek that point to get towards the ideal position accordingly. Chen et al. [24] have proposed pure pursuit (PP) and proportional-integral (PI) based combined steering controller for smooth path tracking in self-driving vehicles. Besides, the authors have designed low pass filters 


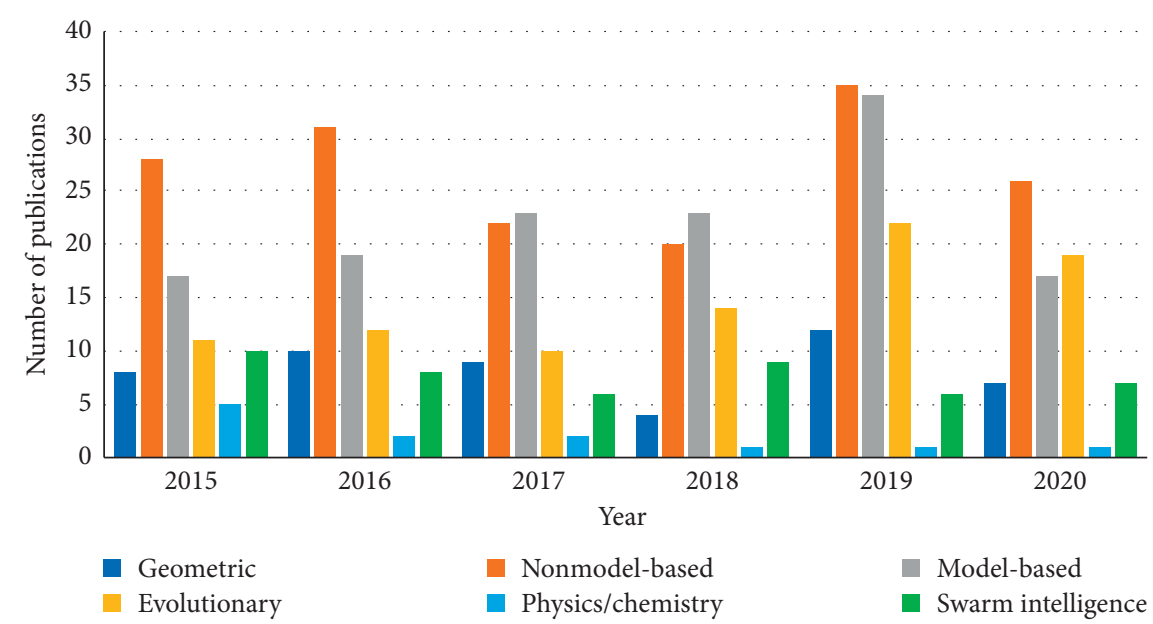

(a)

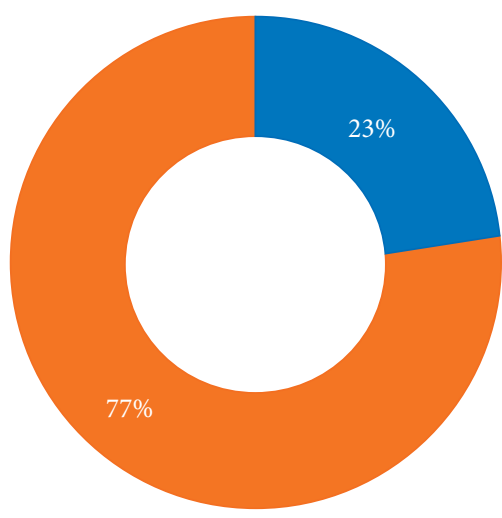

Conferences Journals

(b)

FIGURE 1: Existing research contributions. (a) Research studies (published) regarding steering control systems ranging from 2015 to 2020. (b) Distribution of journal/conference research articles cited in this study.

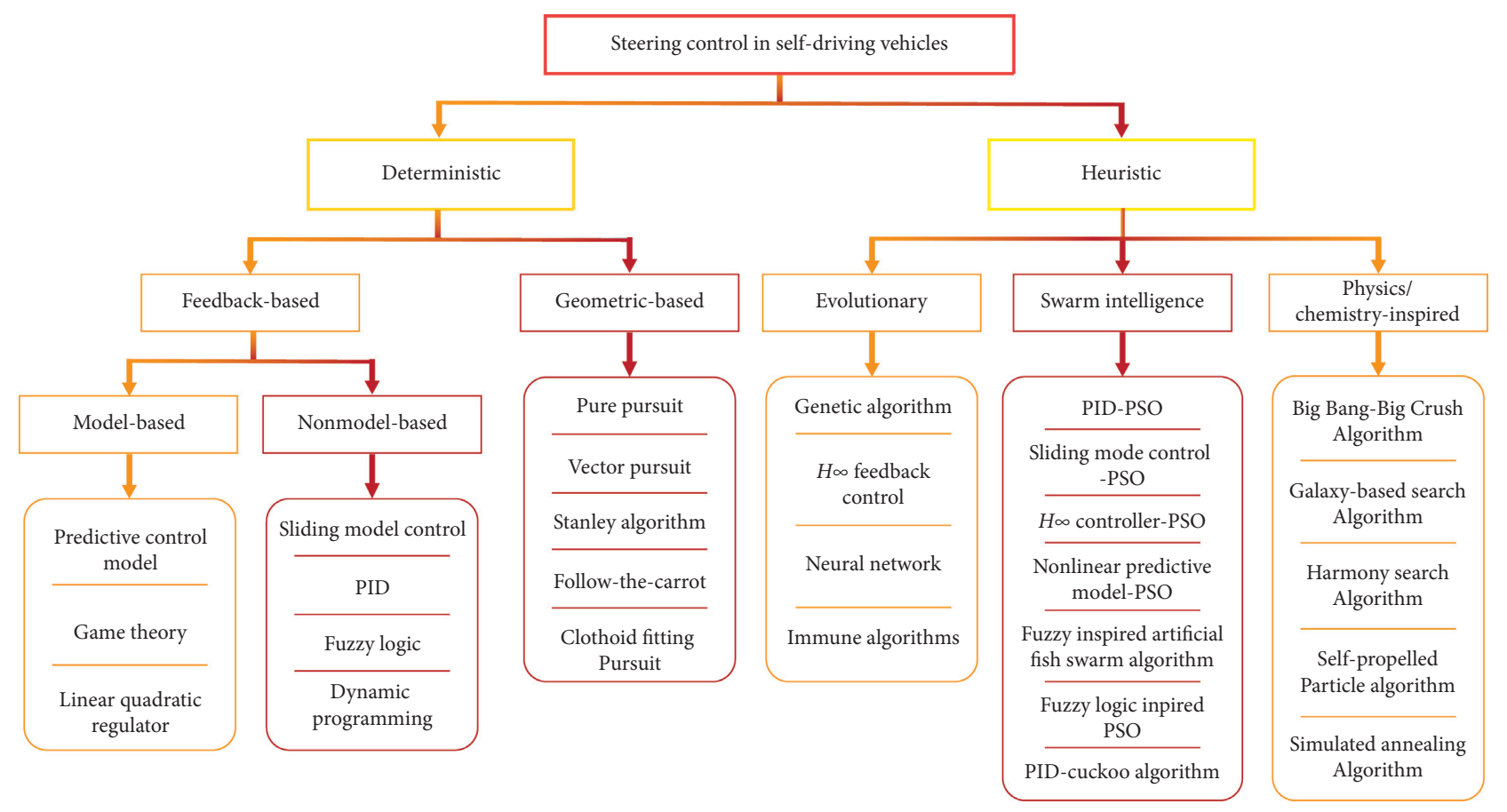

Figure 2: Taxonomy of steering systems.

to cater to the variations in steering angle estimation to improve steering stability in self-driving vehicles. The proposed system has been evaluated in the CARLA simulator to demonstrate the effectiveness of the system. However, the cutting corner problems have been commonly observed in the classic pure pursuit methods [36].

In this regard, Park and Han [25] introduced a lateral steering control system based on an adaptive pure pursuit method for self-driving vehicles to reduce the cut corner tendencies in automated steering systems. Moreover, proportional-integral (PI) control theory has been applied in the lateral offset of the steering wheels to minimize the tracking error in self-driving vehicles. In another research work, Park et al. [31] presented pure pursuit-based automated steering control algorithm for trajectory tracking in self-driving vehicles. The proposed algorithm computes the steering angle considering the pure pursuit parameters, that is, vehicle heading, lateral offset, and look-ahead distance, and generates instructions to the steering controller to actuate accordingly. Similarly, Andersen et al. [32] have proposed a pure pursuit-based steering control method for lateral motion control in self-driving vehicles. The authors have also presented contemporary steering control rules, following the kinematic equation of motion of vehicles to 
improve the stability in steering systems. However, the minimization of errors in the steering system is still a challenging task. To reduce the error rate in an automated steering system, Li et al. [36] have proposed PI-PP based steering estimation and control algorithm considering the velocity of a vehicle and look-ahead points to maintain the steering in curvy road conditions. Likewise, Shan et al. [37] have presented a geometric controller-based CF-pursuit approach to measure the steering angle and adjust the lookahead parameter to control the motion of self-driving vehicles in the road curvatures.

Though, the abovementioned methods are achieved in limited evaluation scope. But the matter of fact is that the performance of pure pursuit methods is based on the lookahead distance, which is a crucial tuning property; well choosing the look-ahead distance needs to be done carefully, as too shorter look-ahead distance leads to a possible fluctuation in control, whereas too long look-ahead distance leads to cut corner issues and a steady-state error occurs at high speed. Moreover, the limitations of the abovementioned methods are elaborated in Table 1.

(2) Stanley. In 2005, a Stanley based steering control method has been proposed which demonstrated better applicability as compared to pure pursuit methods in terms of minimization of cut corners problems at high speed $[33,40]$. It is a nonlinear geometric method that estimates the steering wheel angle through an angular and lateral deviation of the vehicle [33] and minimizes the path tracking error by computing the heading and lateral error of the vehicle [41]. However, a few problems have been observed in the existing methods such as lack of tracking accuracy and global bility in steering control, as these methods require a purely smooth road surface to maintain their accuracy. To address these issues, Hoffmann et al. [33] presented a nonlinear steering controller for self-driving vehicles to follow a trajectory on off-road terrain. The proposed controller considers the parameters, that is, orientation, curvature, and speed of a vehicle to control the heading of self-driving vehicles on a defined trajectory. Moreover, the authors have considered the kinematic equation of motion of vehicle for stability in the proposed controller. Similarly, Snider [38] and Andersen et al. [32] have discussed in their research studies that the performance of Stanley controllers is greatly influenced at high speed of vehicles because raise in acceleration patterns increases external disturbance and steady-state error which ultimately leads to overshoot problem.

(3) Vector Pursuit. Vector pursuit is another geometric technique that uses the current position and orientation of the vehicle to determine the desired lateral control of the vehicle. Wit et al. [42] have presented a vector pursuit method to control the motion of nonholonomic grounded vehicles. To evaluate the performance of the presented vector pursuit method, the authors have performed experiments and simulations in real time with the navigation test vehicle (NTV). Moreover, they presented the comparison of geometry vector pursuit with other geometric algorithms concerning different speeds and look-ahead distance.
Therefore, the comparison has demonstrated that vector pursuit is more reliable and less sensitive to large heading error than to other geometric approaches. However, vector pursuit algorithms have a heavy complex calculation because they are based on the screw technique that was introduced by Robert Stawell in 1900 [34]. In another research work, Yeul et al. [39] have proposed a vector pursuit-based optimum steering control method to stabilize the steering system in tracked vehicles on the deep-sea soft cohesive surface. To prove the effectiveness of the proposed system, the authors have demonstrated a drawbar Pull test and numerical simulations of the proposed controller. But the matter of fact is that the application of the proposed controller is restricted to tracked vehicles only. Moreover, the authors have not provided any scheme for practical real-time validation of the proposed controller.

To provide a summarized perspective of the abovediscussed geometric-based steering control methods, research contributions along with the considered parameters, testbeds, advantages, and limitations are highlighted in Table 2.

2.1.2. Feedback-Based Method. Feedback-based steering control methods are based on the feedback error which generally focus on the input and the output of the system and ignore the motion law. The feedback steering methods comprised linear state feedback on directional deviations, lateral path deviations, and their derivatives. One of the main advantages of this controller is that a well-constructed feedback controller is not sensitive as compared to geometric-based steering control methods [24]. In the literature, feedback-based steering control methods are categorized into (i) model-based and (ii) nonmodel-based steering control methods [43].

(1) Model-Based Feedback Methods. Model-based methods are mathematical models basically, which are widely used to determine the control strategies of self-driving vehicles. As compared to the abovementioned geometric methods, these methods consist of complex mathematical structures. Model-based approaches make all possible predictions about the problem domain in the form of a model, and this paradigm has helped to understand and solve the real problem. In the literature, most of the model-based control methods are proposed to address the issues of automated steering control problems such as instability and parametric uncertainties. Some of the commonly used model-based controllers are model predictive control (MPC), linearquadratic regulator (LQR), neural network, and game theory. A critical insight of these methodologies in terms of steering control systems is described in the following sections (see Table 3):

(a) Model predictive control (MPC)

MPC is a model-based feedback control method that utilizes a mathematical model to predict the optimal control strategy in self-driving vehicles. One of the main edges of MPC-based steering control methods 
TABLE 1: Geometric-based steering control in self-driving vehicles.

\begin{tabular}{|c|c|c|c|c|c|c|}
\hline $\mathrm{A}$ & B & $\mathrm{C}$ & $\mathrm{D}$ & $\mathrm{E}$ & $\mathrm{F}$ & $\mathrm{G}$ \\
\hline $\begin{array}{l}\text { Chen et al. } \\
\text { [24] }\end{array}$ & & $\begin{array}{c}\text { Proposed the PP-PI } \\
\text { controller based on a } \\
\text { combination of pure } \\
\text { pursuit and } \\
\text { proportional-integral }\end{array}$ & $\begin{array}{l}\text { Steering angle, radius, } \\
\text { look-ahead error, } \\
\text { lateral/heading error, } \\
\text { PID parameters }\end{array}$ & & $\begin{array}{l}\text { Effectively reduced the } \\
\text { dependence on the look- } \\
\text { ahead, achieved smaller } \\
\text { tracking error and better } \\
\text { steering smoothness }\end{array}$ & $\begin{array}{l}\text { Speed's effects on the } \\
\text { tracking have not } \\
\text { been discussed and } \\
\text { vehicle dynamics are } \\
\text { ignored }\end{array}$ \\
\hline $\begin{array}{l}\text { Park and } \\
\text { Han [25] }\end{array}$ & & $\begin{array}{l}\text { Presented adaptive pure } \\
\text { pursuit algorithm-based } \\
\text { steering controller using } \\
\quad \text { PI control theory }\end{array}$ & $\begin{array}{c}\text { Cornering stiffness, } \\
\text { kinematic parameters, } \\
\text { lad, steering angle, } \\
\text { lateral offset angle, PID } \\
\text { parameters }\end{array}$ & & $\begin{array}{l}\text { Adaptive pure pursuit } \\
\text { reduces the path tracking } \\
\text { error to } 4.0 \text { more than } \\
\text { conventional pure } \\
\text { pursuit }\end{array}$ & $\begin{array}{l}\text { Neglected the effect } \\
\text { of throttle brake } \\
\text { controller }\end{array}$ \\
\hline $\begin{array}{l}\text { Andersen } \\
\text { et al. [32] }\end{array}$ & $\begin{array}{c}\text { Pure } \\
\text { pursuit }\end{array}$ & $\begin{array}{l}\text { Proposed the steering } \\
\text { control law for the } \\
\text { alternative formulation } \\
\text { to the pure pursuit path } \\
\text { tracking algorithm. }\end{array}$ & $\begin{array}{l}\text { Kinematic parameter, } \\
\text { steering angle, root } \\
\text { mean square RMS } \\
\text { errors, cross-track error }\end{array}$ & & $\begin{array}{l}\text { RMS cross-track error } \\
\text { reduced up to } 46 \% \text {, and } \\
\text { overcame corner-cutting } \\
\text { and overshoot problem }\end{array}$ & $\begin{array}{l}\text { The theoretical } \\
\text { derivation of the } \\
\text { performance } \\
\text { limitations of the } \\
\text { controller has not } \\
\text { been presented }\end{array}$ \\
\hline $\begin{array}{l}\text { Shan et al. } \\
\text { [36] }\end{array}$ & & $\begin{array}{c}\text { Presented CF-pursuit- } \\
\text { based fuzzy system to } \\
\text { measure the steering } \\
\text { angle and adjust the } \\
\text { look-ahead parameter to } \\
\text { control the motion of the } \\
\text { AV }\end{array}$ & $\begin{array}{l}\text { Curve angle, look-ahead } \\
\text { distance, radius, } \\
\text { steering angle, vehicle } \\
\text { heading, kinematic } \\
\text { parameters }\end{array}$ & ractical & $\begin{array}{l}\text { Maintained stability in } \\
\text { steering controller, } \\
\text { achieved less cross-track } \\
\text { error }\end{array}$ & $\begin{array}{c}\text { Velocity has not been } \\
\text { considered that badly } \\
\text { influenced the } \\
\text { performance of the } \\
\text { steering controller }\end{array}$ \\
\hline $\begin{array}{l}\text { Hoff. et al. } \\
\text { [37] }\end{array}$ & Stanley & $\begin{array}{l}\text { Presented nonlinear } \\
\text { steering control law } \\
\text { based on the Stanley } \\
\text { algorithm for AV to } \\
\text { track a trajectory on off- } \\
\text { road terrain }\end{array}$ & $\begin{array}{l}\text { Kinematic parameters, } \\
\text { steering angle, steering } \\
\text { servo meter, stiffness }\end{array}$ & & $\begin{array}{c}\text { Achieved root mean } \\
\text { square cross-track } 0.1 \mathrm{~m} \\
\text { less than the standard } \\
\text { error }=0.08\end{array}$ & $\begin{array}{l}\text { Overshoot and the } \\
\text { steady-state error } \\
\text { occurred at high } \\
\text { speed }\end{array}$ \\
\hline $\begin{array}{l}\text { Wit et al. } \\
\text { [38] }\end{array}$ & & $\begin{array}{l}\text { Presented vector } \\
\text { tracking method based } \\
\text { on screw theory to deal } \\
\text { with a vehicle heading }\end{array}$ & $\begin{array}{l}\text { Unit/moment vector, } \\
\text { kinematic parameters, } \\
\text { translation/rotation/ } \\
\text { instantaneous screw, } \\
\text { look-ahead point }\end{array}$ & & $\begin{array}{l}\text { Accurately handle the } \\
\text { large error, less reliance } \\
\text { on lad, more robust than } \\
\text { stanley and pursuit } \\
\text { method }\end{array}$ & $\begin{array}{l}\text { The complex } \\
\text { calculation required } \\
\text { expertise to tune } \\
\text { parameters }\end{array}$ \\
\hline $\begin{array}{l}\text { Yeul et al. } \\
\text { [39] }\end{array}$ & rsuit & $\begin{array}{c}\text { Proposed geometric } \\
\text { control approach based } \\
\text { on vector pursuit } \\
\text { technique to improve the } \\
\text { stability in steering } \\
\text { control }\end{array}$ & $\begin{array}{c}\text { Translation/rotation/ } \\
\text { instantaneous screw, } \\
\text { weighting factors, } \\
\text { kinematic parameters, } \\
\text { look-ahead point, slid } \\
\text { slip, radius }\end{array}$ & Simulation & $\begin{array}{l}\text { Achieved less changing } \\
\text { rate of heading error, the } \\
\text { average slip of right and } \\
\text { left track has been } \\
\text { recorded as } 0.0378 \text { and } \\
0.0383 \text {, respectively }\end{array}$ & $\begin{array}{c}\text { Has not been verified } \\
\text { in a real or simulated } \\
\text { environment }\end{array}$ \\
\hline
\end{tabular}

A: authors, B: technique, C: contribution, D: considered parameters, E: testbed, F: strengths, and G: limitations.

TABLE 2: Detail model's parameters.

$\begin{array}{ll}\text { Models } & \text { Regarding parameters }\end{array}$

Kinematics model Acceleration, speed, lateral velocity, longitudinal velocity, lateral and longitudinal displacement/change in position Dynamic model Lateral and longitudinal forces, energy, yaw momentum of the system, yaw rate, yaw rotation, yaw angle Proportional gain, integral gain, derivate gain

is that these controllers are capable of handling multi-input multioutput (MIMO) variables, which can tolerate the real-time input processing in automated steering control systems. Besides, the MPCbased steering control methods can handle constraints and nonlinearities systematically.

To address the issues in the abovementioned geometricbased steering control methods, MPCs have been considered due to their sophisticated architecture, to improve the stability of an automated steering control system in self-driving vehicles. In this regard, Nam et al. [44] presented the MPC-based dynamic steering controller to introduce evasive steering manoeuvring of self-driving vehicles. Respectively, Wang et al. [45] proposed a fuzzy-MPC-based combined controller design for automated steering control in self-driving vehicles. It is important to mention that the authors integrated a fuzzy control algorithm to adjust the weight of the cost function of the regular MPC. However, these models do not incorporate the uncertainties in roll-over 
TABLE 3: Model-based steering control in self-driving vehicles.

\begin{tabular}{|c|c|c|c|c|c|c|}
\hline A & $\mathrm{B}$ & $\mathrm{C}$ & $\mathrm{D}$ & $\mathrm{E}$ & $\mathrm{F}$ & G \\
\hline [44] & \multirow{2}{*}{ MPC } & $\begin{array}{l}\text { Proposed MPC design } \\
\text { based on steering and } \\
\text { vehicle model dynamics } \\
\text { for evasive steering } \\
\text { manoeuvres }\end{array}$ & $\begin{array}{c}\text { Kinematic and dynamic } \\
\text { parameter, steer angle, } \\
\text { stiffness }\end{array}$ & Simulation & $\begin{array}{l}\text { Calculated the desired } \\
\text { steering angle within the } \\
\text { suitable voltage. Physical } \\
\text { limits and constraints have } \\
\text { been explicitly handled }\end{array}$ & $\begin{array}{l}\text { The proposed MPC have } \\
\text { been only worked under the } \\
\text { allowable voltage ranges }\end{array}$ \\
\hline [45] & & $\begin{array}{c}\text { Proposed an integrated } \\
\text { MPC-fuzzy approach for } \\
\text { the steering control of an } \\
\text { AV }\end{array}$ & $\begin{array}{l}\text { Steering angle, side slip } \\
\text { angle, kinematic and } \\
\text { dynamic parameters, } \\
\text { stiffness }\end{array}$ & Simulation & $\begin{array}{c}\text { The proposed MPC model } \\
\text { performed } 82 \% \text { superior to } \\
\text { the classic MPC }\end{array}$ & $\begin{array}{l}\text { Suspension moment, slip } \\
\text { phenomena, and } \\
\text { aerodynamic influences } \\
\text { have been neglected in the } \\
\text { validation process }\end{array}$ \\
\hline [49] & \multirow[t]{2}{*}{ LQR } & $\begin{array}{l}\text { Presented the LQG with } \\
\text { adaptive Q-matrix to } \\
\text { design the steering } \\
\text { controller }\end{array}$ & $\begin{array}{c}\text { Kinematic and dynamic } \\
\text { parameter, steer angle, } \\
\text { stiffness }\end{array}$ & Practical & $\begin{array}{l}\text { Performed explicit in } \\
\text { different speeds and in } \\
\text { large curvatures and } \\
\text { achieved lateral offset of } \\
0.4 \mathrm{~m}\end{array}$ & $\begin{array}{c}\text { Did not consider variables, } \\
\text { that is, momentary } \\
\text { fluctuations, lateral } \\
\text { intensity, and model } \\
\text { uncertainty during the } \\
\text { validation process }\end{array}$ \\
\hline$[50]$ & & $\begin{array}{c}\text { Proposed a novel } \\
\text { approach-based RLQR } \\
\text { controller for the lateral } \\
\text { control of an AHDV }\end{array}$ & $\begin{array}{c}\text { Articulation angle, } \\
\text { steering angle, } \\
\text { kinematic and dynamic } \\
\text { parameters }\end{array}$ & Simulation & $\begin{array}{l}\text { Performed well for an } \\
\text { extension of payloads, } \\
\text { then the H controller }\end{array}$ & $\begin{array}{l}\text { The proposed model has not } \\
\text { been tested in real-time } \\
\text { controlled or in dynamic } \\
\text { road scenarios }\end{array}$ \\
\hline [54] & \multirow{2}{*}{$\begin{array}{l}\text { Game } \\
\text { theory }\end{array}$} & $\begin{array}{l}\text { Modeling of manual } \\
\text { steering interaction with } \\
\text { an automated steering } \\
\text { system based on } \\
\text { cooperative game theory }\end{array}$ & $\begin{array}{c}\text { Steering angle, } \\
\text { kinematic and dynamic } \\
\text { parameters, state } \\
\text { matrix, cornering } \\
\text { stiffness, steering ratio }\end{array}$ & \multirow{2}{*}{ Case study } & $\begin{array}{l}\text { Successfully developed } \\
\text { Pareto's steering strategy } \\
\text { to control the steering } \\
\text { angle efficiently }\end{array}$ & $\begin{array}{l}\text { Control parameters of the } \\
\text { proposed strategy have not } \\
\text { been identified through a } \\
\text { standard system } \\
\text { identification approach }\end{array}$ \\
\hline [56] & & $\begin{array}{l}\text { Proposed an innovative } \\
\text { dynamic control } \\
\text { authority allocation } \\
\text { strategy for the game- } \\
\text { based shared control }\end{array}$ & $\begin{array}{l}\text { Side-slip angle, } \\
\text { kinematic and dynamic } \\
\text { parameters, weight/ } \\
\text { input/output matrices, } \\
\text { state/output vectors }\end{array}$ & & $\begin{array}{c}\text { The proposed strategy has } \\
\text { ensured the stability of the } \\
\text { vehicle }\end{array}$ & $\begin{array}{l}\text { Case studies could not be } \\
\text { consider as an authoritative } \\
\text { method for validating the } \\
\text { proposed solution }\end{array}$ \\
\hline
\end{tabular}

A: reference, B: technique, C: contribution, D: considered parameters, E: testbed, F: strengths, and G: limitations.

collision control. To address this issue, Cai et al. [46] have presented a path tracking steering control system based on an MPC unit and an active safety steering control unit. The authors considered a dynamic vehicle model in the proposed steering controller to avoid vehicle roll-over collisions. Similarly, Sun et al. [47] proposed a linearized model-based steering controller to minimize lateral deviation under high speeds and large lateral acceleration in self-driving vehicles. In another research work, Sun et al. [48] presented an MPC controller to improve the effectiveness of automated steering control systems by minimizing switched tracking errors with the lateral deviation of self-driving vehicles under different acceleration patterns.

The abovementioned MPC-based steering control methods achieved significant performance in the defined testbeds. However, these systems require a highpowered processing unit with a memory unit to maintain their real-time computation performance at each time step. Moreover, MPCs still face convergence and high computational complexity issues that influence their effectiveness in real-time dynamic conditions. Besides, the performance of the MPC-based steering controller is prejudiced under high-speed conditions. (b) Linear-quadratic regulator

The linear-quadratic regulator (LQR) is a wellknown method that provides optimally controlled feedback gains to enable closed-loop stability and high-performance design of the system. One of the main advantages of LQR is that these methods are capable of real-time computation due to their sophisticated structure. However, the LQR based system does not consider the constraints while execution which influences their efficiency.

In the last couple of years, many researchers put a significant amount of time and effort into optimizing and calibrating the steering controller to obtain consistent steering operation and reliable steering performance in high speed and road curvature deviations. In this regard, Lee et al. [49] presented a linear-quadratic Gaussian (LQG) model-based controller design which systematically addresses the additive bias factor caused by path planning and localization. Additionally, the authors have presented a regulator designed for automated steering system tuning for different acceleration patterns of vehicles. However, lateral stability and parametric uncertainties have been identified as key issues in the literature. Besides, the current control 
techniques often require offline tuning parameter modification, which is not realistic.

To resolve the abovementioned issues, Barbosa et al. [50] proposed a robust linear-quadratic regulator(RLQR-) based steering controller for lateral regulation for an articulated heavy-duty vehicle (AHDV) that does not rely on offline adjustment of tuning parameters. To ensure stability and manoeuvrability in articulated vehicles, Kim et al. [51] have introduced an active steering controller, combined with a tractor and trailer control mechanism. In another study, Jiang and Xiao [52] proposed a state-feedback-based optimization control algorithm for four-wheel steering (4WS) control of forklift along with the control method. The proposed method is applied to the two-degree-offreedom (2-DOF) and three-degree-of-freedom (3DOF) models of $4 \mathrm{WS}$ to demonstrate the efficacy of the proposed system. Saito et al. [53] have designed a mathematical model and controller for the steering system of the vehicle, where the control of steering torque has been extended to transfer feedback gains from the LQR controller. Besides, the authors have been proposed a theoretical dual-control driver assistance algorithm using an LQR to control the steering torque. However, the proposed methods are only applicable in straight road conditions, where the chance of tweak handling is low as compared to curvy road scenarios. Therefore, there is a need to improve LQR-based steering control methods, which could be employed in curvy/dynamic roads.

(c) Game theory

In the literature, the problem of interaction has been discussed in the context of a driver controlling a vehicle mounted with an automatic steering system, where the driver and the automated system have different target paths and try to apply steering angles to the vehicle independently. Game theory offers a mechanistic basis for understanding the diver-automation attraction.

In this regard, $\mathrm{Na}$ and Cole [54] presented the modeling of manual steering interaction with an automated steering system using the cooperative game theory. Moreover, they have considered the distributed MPC approach to design the Pareto cooperative steering strategies to improve the performance of the system in following a target path. In another research work, $\mathrm{Na}$ and Cole [55] presented a case study considering four paradigms, that is, (i) decentralized, (ii) noncooperative Nash, (iii) noncooperative Stackelberg and, and (iv) cooperative Pareto to investigate a manual steering interaction with active first steering (AFS) controller through cooperative game theory. Based on the analysis, the authors have provided a detailed insight into optimization problems in steering controllers. Zhu et al. [56] presented a linear-quadratic differential game-based coordinated control system for 4WS vehicle. Moreover, for active $4 \mathrm{WS}$, the planning horizon based quadratic differential game model has been established, and the rear and front-wheel steering angles have been distinguished as two agents. In another research work, $\mathrm{Li}$ et al. [57] proposed a noncooperative game theory for the modeling of humanautomation interaction. Besides, the Nash equilibrium solution for the proposed method has been derived from a distributed MPC (DMPC) approach.

The authors claimed that the abovementioned proposed methods enable the self-driving vehicles to achieve high stability performance and to avoid obstacles in safe manners. However, the verification of proposed techniques has been carried out based on the case studies which could not be considered as an authentic approach to validate the proposed techniques. Therefore, the proposed techniques must be validated through standard simulators or testbeds in a real-world environment. Moreover, game theory-based systems have less practicability which can lead to a highly unrealistic assumption.

(2) Nonmodel-Based Feedback Methods. Nonmodel feedback controller is based on the concept of optimizing the anticipated reward from the real experience, without considering the model or prior experience. The main objective of nonmodel-based feedback methods is to attain the rewards associated with the current and corresponding actions. These controllers do not require any essential details regarding parameters of actuators or manipulators; thus, no mathematical model for the manipulator is required in the execution of these systems. The key nonmodel-based feedback methods that are commonly used for solving the problem of steering control in self-driving cars are proportional-integral-derivative, fuzzy logic, dynamic programming, and sliding mode control. A critical review of the nonmodel-based methods within the perspective of steering control is discussed in the following sections.

(a) Proportional-integral derivate (PID)

In the last couple of decades, extensive research has been carried out on control theory and path tracking methodologies. Among these, PID-based control methods have been widely applied in the steering control of self-driving vehicles. As compared to the abovementioned techniques, the applicability of PID controllers is simple and has robustness towards the steering controller in self-driving vehicles. However, traditional PID controllers do not deal with parameter optimization, are unable to adapt to external environment disturbance, and are computationally complex while steering control in dynamic roads.

In this regard, Baskaran et al. [58] have proposed a PID controller for steering control of self-driving vehicles using voltage spoofing based on braking and throttle modules. In another research work, Zhao et al. [59] introduced an adaptive PID controller for intelligent pioneer AVs to deal with path tracking 
and stability of motion while navigating in an unseen environment. To minimize the computation complexity, Yin et al. [60] have proposed a fuzzy-PID controller for steering control in rice transplanter, for the real-time adjustment of control parameters of the PID controller to obtain optimal steering angle. Similarly, Chen et al. [61] have presented an adaptive fuzzy-PID-based controller for four-wheel-independent-steering (4WIS) electric vehicles (EV). The authors presented an analysis of the four-wheel steering mechanism and derived a relationship between the rear and front-wheel steering angles based on the zero-centroid angle of the vehicle.

In the literature, the pulse width modulation (PWM) controller has been used for steering manoeuvres in the UiTM AV prototype. However, this approach has a few drawbacks such as PWM controllers do not achieve accurate and consistent steering angle output and are computationally complex in terms of convergence. To address this issue, Mohamad et al. [62] presented a PID-based steering controller for UiTM self-driving vehicles to improve steering convergence and steering overshoot problems. The proposed controller can deal with overshooting in a dynamic road environment through a pure PID controller, which demonstrated better applicability as compared to the PWM controller.

For the abovementioned steering control methodologies, simulated testbeds have been utilized with different scenarios to validate the effectiveness of these methods. The claimed results demonstrate the applicability of the proposed steering controllers in the defined scope. However, the authors have not presented any mechanism for real-time infield validation of their proposed methods. Also, the authors did not consider many factors during lateral control of self-driving vehicles such as disturbances by GPS signal attenuation, changing road conditions, and change in vehicle parameters with time. It would be interesting if these issues are also considered in lateral control of self-driving vehicles. Moreover, when the speed is high, external disruptions, that is, wind resistance and road adherence conditions have a significant impact on the performance of the proposed controllers, as tracking error increases with the increase in the speed of self-driving vehicles.

(b) The fuzzy logic-based steering controller

The fuzzy logic controller is another type of nonmodel-based feedback controller which has greater importance in steering control manoeuvre due to its capability to incorporate human brain-inspired knowledge and experience. However, fuzzy logic controller is based on prior knowledge and requires expertise for defining concurrent rules to achieve safe manoeuvring while heading the vehicle towards the destination. Moreover, defining rules becomes unmanageable if the number of variables is larger [63-65].

Many researchers have used fuzzy logic techniques to control the steering module of self-driving vehicles. Vans et al. [63] have presented a human driver behavior inspired by a fuzzy logic-based steering controller for self-driving vehicles. The proposed system extracts the road lane information using a visual sensor, processes it into a designed inference engine, and executes the driving rule to control the steering wheels and velocity of the self-driving vehicle accordingly. Simultaneously, Rastelli and Peñas [64] have proposed a fuzzy logic inference engine based steering controller for self-driving vehicles to predict and execute safe manoeuvring in roundabout complex scenarios. The authors have divided the roundabout scenario into three stages, that is, (i) entrance, (ii) inside, and (iii) exit, and presented a cascade architecture to generate predicted trajectory and execute manoeuvre accordingly. Hodge and Trabia [65] have presented a fuzzy logic based steering controller for the two-axel vehicle. The target steering module has been developed to steer the vehicle towards the target by analysing the steering angle set to the decided target.

In light of actuator constraints such as saturation amplitude of actuators and rate limit, Zhang et al. [66] have presented a fuzzy T-S feedback-based controller comprising fuzzy modeling techniques and a look-ahead method for steering control of the self-driving vehicles. The proposed method takes parametric uncertainties, distance preview rule, and nonlinearities into account which are associated with vehicle mass and cruise control variations. However, during the validation of the proposed controller, the authors have only considered road condition scenarios, while neglecting other external permutations such as extrinsic noise factors. To deal with external disruptions and operating conditions, Zadeh and Taghavifar [67] proposed a fuzzy control approach based on a nonsingleton fuzzy scheme comprised of nonstationary fuzzy sets which are used for estimation of uncertainties and lateral steering control of self-driving vehicles. Aminah et al. [68] have proposed fuzzy logic based steering control approach considering error in yaw rate and steering wheel rotation angle obtained from the IMU sensors to control the heading of the vehicle. $\mathrm{Xu}$ and Norris [69] have proposed a hierarchical fuzzy logic steering control (FLSC) system to improve the efficiency of the trajectory tracking in intelligent vehicles. The authors have presented 35 fuzzy rules for the lateral control which have been validated with the Ackermann and skid-steer simulated vehicle model. In another research work, Abroshan et al. [70] have proposed a fuzzy controller for the articulated 
tractor vehicle to mitigate the off-tracking considering the instant centre of rotation (ICR) while steering manoeuvres in slow speed. In another research, the fuzzy-PID-based compound control method has been devised to control the actuators of the testbed, but the matter of fact is that the PID controller overruns in an undesiring environment [71]. The authors have not presented any scheme to optimize the PID parameters to deal with the unappealing conditions. Pandey et al. [72] have proposed a type-2 fuzzy controller (T2FC) to control the lateral motion of the Differential-Drive Pioneer P3DX Wheeled Robot (DDPWR) through the information provided by IMU/Object detection sensors.

In another research work, Xu et al. [73] have proposed type-2 fuzzy logic and MPC-based combined steering control method along with the customized steering control have been proposed to stabilize the lateral motion in different road conditions. However, steer-by-wire based AVs still require attention to improve the effectiveness in lateral control while manoeuvring. In this regard, $\mathrm{Wu}$ and $\mathrm{Li}$ [74] introduced a fuzzy-neural network-based variable steering control for self-driving vehicles to improve the control unit of the steer-by-wire AVs. Halin et al. [75] have proposed GPS-fuzzy logic-based controller for navigation and path tracking in the unmanned ground vehicles. The proposed system defines the path through the GPS module and a fuzzy inference engine has been devised to control the lateral motion of the steering wheels.

The abovementioned proposed system has been validated in a different simulator in which it achieved satisfactory improvement in the manoeuvrability of the autonomous vehicles. However, one of the most crucial problems in fuzzy logic-based controllers is that its computation time increases with the increase in the complexity of inference engine which prejudices the performance in the real-time environment. Moreover, these controllers only consider the defined rules, which do not cater to the possible constraints of the real-time dynamic road conditions. Furthermore, the authors have not presented any algorithm/scheme for the real-time infield experimentation of the proposed controller considering undesiring road conditions. Besides, the limitations and strengths of the abovementioned proposed strategies are cited in Table 4.

(c) Dynamic programming

Nonmodel-based adaptive dynamic programming (ADP) enabled steering control methods are also motivated by control, biological learning, and enhanced learning. ADP aims to learn adaptive optimal controller iteratively from commutative data information without proper knowledge about system dynamics. Recently, the ADP techniques have been used in a vibrant way to adaptively control selfdriving and connected vehicles [76].

In step with the latest advancement in artificial intelligence, the abilities of autonomous vehicles have been enhanced notably. However, there are still some technical issues needed to be resolved; among these, getting an optimal control law in the steering control system of self-driving vehicles is also an important issue. To address this problem, Lu et al. [77] have proposed a steering controller based on policy iteration ADP to get optimal control in steering systems of self-driving vehicles. Moreover, cost-effective offline plus online training for network models has also been presented. In another research work, Zhu et al. [78] have presented an innovative steering controller comprised of neural dynamic programming (NDP) for path tracking in selfdriving vehicles. The proposed controller incorporates the NDP-based module and Stanley method, where the NDP-based module has been used to boost the functionality of the Stanley technique. However, there is a flaw in the proposed controller that has been encountered while simulation-based evaluation of the proposed controller that there is a slight vibrating in path tracking process which threats the physical applications of the controller which ultimately leads to lack of comfort and safety. Huang et al. [79] proposed a data-driven based dynamic programming strategy to design a steering controller without considering the current internal states of the driver and vehicle. Besides, the steering controller interacts with the driver via robust ADP and output control theory to achieve optimal reliability of steering control while lane-keeping.

One of the main limitations of the abovementioned dynamic programming-based steering control techniques is that these systems are evaluated in a simulated environment, where the actual performance of controllers cannot be validated. Moreover, researchers did not consider external disturbances and parameter tuning while evaluating the proposed controllers. Hence, there is a need to introduce a real-time parameter tuning mechanism for steering controllers to improve the convergence rate of these systems. A tabular representation of the abovementioned methodologies is provided in Table 4.

(d) Sliding mode controllers (SMCs)

Sliding mode controllers (SMC) have been considered as a powerful robust control technique because of their exceptional capabilities such as instant response, strong robustness towards parameter perturbation, and external disturbance in nonlinear time-varying systems. Due to their sophisticated architecture, a wide range of applications based on SMCs are introduced during the past couple of decades [80]. 
TABLE 4: Nonbased steering control in self-driving vehicles.

\begin{tabular}{|c|c|c|c|c|c|c|}
\hline $\mathrm{A}$ & $\mathrm{B}$ & $\mathrm{C}$ & $\mathrm{D}$ & E & $\mathrm{F}$ & G \\
\hline$[59]$ & \multirow{2}{*}{ PID } & $\begin{array}{l}\text { Designed the adaptive } \\
\text { PID controller for the } \\
\text { intelligent pioneer AV }\end{array}$ & $\begin{array}{c}\text { PID parameters, } \\
\text { stiffness, yaw moment } \\
\text { of inertia, look-ahead } \\
\text { distance }\end{array}$ & \multirow{2}{*}{ Simulation } & $\begin{array}{l}\text { Mitigate the error to } 0.5 \mathrm{~m} \text {, } \\
\text { performed better than } \\
\text { conventional PID }\end{array}$ & $\begin{array}{l}\text { Ignored external } \\
\text { disturbances, that is, } \\
\text { GPS signal } \\
\text { attenuation, changing } \\
\text { road conditions }\end{array}$ \\
\hline$[61]$ & & $\begin{array}{l}\text { Presented steering } \\
\text { strategy based on } \\
\text { adaptive fuzzy-PID } \\
\text { controller for ( } 4 \mathrm{WIS}) \\
\text { electric vehicle (EV) }\end{array}$ & $\begin{array}{l}\text { Vehicle mass, } \\
\text { stiffness, side slip } \\
\text { angle, kinematic/ } \\
\text { dynamic parameters, } \\
\text { heading angle }\end{array}$ & & $\begin{array}{l}\text { The max lateral } \\
\text { displacement error value is } \\
-0.4119 \mathrm{~m} \text { and the heading } \\
\text { angle error is } 3.274 \text {, at } \\
20 \mathrm{~m} / \mathrm{s} \text { speed }\end{array}$ & $\begin{array}{l}\text { Did not robust to } \\
\text { external disruption, } \\
\text { detecting failure } \\
\text { increases as the speed } \\
\text { increases }\end{array}$ \\
\hline$[63]$ & \multirow{2}{*}{ Fuzzy logic } & $\begin{array}{l}\text { Proposed a human } \\
\text { inspired fuzzy logic- } \\
\text { based steering } \\
\text { controller for self- } \\
\text { driving vehicles }\end{array}$ & $\begin{array}{l}\text { Lateral/heading/ } \\
\text { tracking error, } \\
\text { steering angle, linear } \\
\text { velocity }\end{array}$ & Practical & $\begin{array}{l}\text { The proposed controller } \\
\text { performed explicitly on the } \\
\text { straight road having slight } \\
\text { curvature }\end{array}$ & $\begin{array}{c}\text { Constraints have not } \\
\text { been set for the tuning } \\
\text { of the controller } \\
\text { parameters }\end{array}$ \\
\hline$[67]$ & & $\begin{array}{l}\text { Proposed a fuzzy } \\
\text { control method based } \\
\text { on a nonsingleton } \\
\text { fuzzy scheme }\end{array}$ & $\begin{array}{l}\text { Heading angle, side } \\
\text { slip angle, cornering } \\
\text { stiffness, steering } \\
\text { angle, kinematic/ } \\
\text { dynamic parameters }\end{array}$ & \multirow{3}{*}{ Simulations } & $\begin{array}{l}\text { Robust against external } \\
\text { disturbances, reduced } \\
\text { computational cost of } \\
\text { conventional type } 2 \text { fuzzy } \\
\text { system }\end{array}$ & $\begin{array}{l}\text { Does not apply any } \\
\text { conditions on the } \\
\text { control signals }\end{array}$ \\
\hline$[76]$ & \multirow{2}{*}{$\begin{array}{c}\text { Dynamic } \\
\text { programming }\end{array}$} & $\begin{array}{l}\text { Proposed steering } \\
\text { controller based on } \\
\text { ADP to get the optimal } \\
\text { control for the AV }\end{array}$ & $\begin{array}{l}\text { Offset angle, steering } \\
\text { angle }\end{array}$ & & $\begin{array}{l}\text { Increased degree of } \\
\text { constancy and smoothness } \\
\text { in the steering process }\end{array}$ & $\begin{array}{l}\text { Ignored external } \\
\text { disturbances, not } \\
\text { enough robust, } \\
\text { validated on constant } \\
\text { speed }\end{array}$ \\
\hline$[77]$ & & $\begin{array}{c}\text { Presented an NDP- } \\
\text { steering controller for } \\
\text { the path tracking of } \\
\text { ALVs }\end{array}$ & $\begin{array}{l}\text { Lateral/angle/tracking } \\
\text { error, current speed, } \\
\text { handcrafted } \\
\text { coefficient, discount } \\
\text { factor }\end{array}$ & & Tracked vehicle accurately & $\begin{array}{l}\text { No tune parameter } \\
\text { used for convergence, } \\
\text { occurring slight } \\
\text { vibrating error }\end{array}$ \\
\hline$[78]$ & \multirow{2}{*}{ SMC } & $\begin{array}{l}\text { Presented backstepping } \\
\text { SMC for the steering } \\
\text { manoeuvre of } \\
\text { unmanned vehicles }\end{array}$ & $\begin{array}{l}\text { Dynamic/kinematic } \\
\text { parameters, stiffness, } \\
\text { heading deviation, } \\
\text { slide slip angle, } \\
\text { direction angle }\end{array}$ & $\begin{array}{l}\text { Simulation/ } \\
\text { practical }\end{array}$ & $\begin{array}{l}\text { Achieved the minimum } \\
\text { lateral error }=0.029 \mathrm{~m} \\
\text { Reduced steady-state error }\end{array}$ & $\begin{array}{c}\text { Experiments have not } \\
\text { been carried out in } \\
\text { high speed }\end{array}$ \\
\hline$[79]$ & & $\begin{array}{l}\text { Proposed a sliding } \\
\text { model control-based } \\
\text { emergency steering } \\
\text { controller }\end{array}$ & $\begin{array}{l}\text { Steering angle, slip } \\
\text { angles, cornering } \\
\text { stiffness's, dynamic } \\
\text { and kinematic } \\
\text { parameters }\end{array}$ & $\begin{array}{l}\text { Simulation/ } \\
\text { CarSim }\end{array}$ & $\begin{array}{l}\text { Achieved path tracking } \\
\text { error }=0.16 \mathrm{~m} \\
\text { Heading error }=0.95^{\circ} \mathrm{m} \\
\text { Lateral distance }=0.51 \mathrm{~m}\end{array}$ & $\begin{array}{c}\text { The proposed solution } \\
\text { has not been validated } \\
\text { in real-time } \\
\text { environment }\end{array}$ \\
\hline
\end{tabular}

A: reference, B: technique, C: contribution, D: considered parameters, E: testbed, F: strengths, and G: limitations.

Motion control in self-driving vehicles includes an automatic steering system which is significantly influenced by disruption of the parameters which leads to instability in steering control. To overcome this problem, Wang et al. [81] proposed an automatic steering control strategy comprising the backstepping slide mode control theory for selfdriving vehicles. Besides, the authors have presented a time-varying dynamic variable and vehicle models fusion-based steering manoeuvring method to maximize tracking accuracy. Similarly, $\mathrm{He}$ et al. [22] have proposed a sliding model control based emergency steering controller for self-driving vehicles to predict the collision scenario and execute safe manoeuvring to ensure collision avoidance while considering the stability of the vehicle.
In another research work, Dai et al. [82] have proposed a kinematic model and slide mode control based hybrid approach to estimate steering angle and control four independent wheels of self-driving vehicles. To optimize the control parameters, the authors have employed the PSO algorithm to stabilize velocity and acceleration control, respectively. Norouzi et al. [83] presented a steering controller based on the integration of sliding mode and backstepping controller for lateral control in self-driving vehicles. Besides, the authors have employed the Lyapunov stability theorem for the stability of the proposed controller and utilized the PSO technique to fine-tune the finest values of parameters of the controller. Sun et al. [84] proposed a nested adaptive supertwisting sliding mode (NASTSM) control strategy for the SBW system in 
self-driving vehicles. In the proposed control strategy, a nested adaptive law has been adopted to deal with complex time-varying external disturbances, and an STSM control component has been used to sustain finite-time convergence and chattering-alleviation.

The abovementioned proposed approaches have demonstrated better applicability in terms of higher tracking accuracy with lower dependence on plant models. However, the proposed strategy comprises complex algorithmic structure that requires a heavy processing unit to implement the proposed system in real-time applications; consequently, it increases the cost of the system by $60 \%$. Furthermore, the authors have not validated the proposed strategy with real scenarios at high speed under different road environments and have not paid attention to the computation time of the proposed controller. The strengths along with limitations of the abovementioned methods are highlighted in Table 4.

\subsection{Heuristic Steering Control Methods}

Definition 2. According to Siddique and Adeli [27], the heuristic methods always produce different output for the given input in the different runs.

The heuristic methods inherent some randomness; however, their exploration capabilities are enhanced, but operation capabilities are reduced [28]. The parameter values and initial conditions in a heuristic system contribute to a series of different outputs. Furthermore, in contrast to a deterministic method, these methods can show different behaviors on different runs for the same input. These methods can be distinct from run to run for an algorithm. These methods are nonpredictive because the outcome of a process is not objectively determined, due to a lack of understanding of a cause/effect relationship, or an inability to recognize initial conditions. However, these methods are more proficient in handling NP-hard problems (i.e., problems that have no known solutions in polynomial time) [27].

There is a variety of nature-inspired heuristic methods reported in the literature that have been further categorized into the Bioinspired Evolutionary, Swarm Intelligence, and Physics-Chemistry Inspired methods. Their short review will be part of the next subsection [34].

2.2.1. Evolutionary Methods. Evolutionary methods are heuristic search, parallel, global, or cost-based optimization methods, based on the principles of nature that have been introduced by Darwin in 1859. EAs are well-known, classical, and well-established algorithms of nature-inspired algorithms focused on the biological evolution of nature that is responsible for the creation of all living beings on Earth and the techniques they use to communicate with each other. This influential concept theory is used by EAs to find solutions to challenging problems [85]. The most
Bioinspired Evolutionary methods that played a vital role in the performance of the steering control of the autonomous vehicle are genetic algorithms, $\mathrm{H}$ controller, Neuroevolution, and Immune algorithm.

(1) Genetic Algorithms. The evolutionary based genetic algorithm (GA) has introduced by John Holland in 1960, for the solution of constrained and unconstrained optimization problems. The GA works by repeatedly modifying a random population of individual solutions to a problem, evaluating those solutions, and then using cloning, recombination, and mutation to create new solutions to the problem. The edge of genetic algorithms over traditional methods is that it can avoid trapping in local optima and provide the global optimum solution to a problem because GAs search parallels a population of points. Moreover, the reasons to use a GA are as follows: it can find a good solution in less time of computation, is easily modified, and is adaptable to different problems. Furthermore, the genetic algorithm has proven efficient for a wide variety of optimization problems.

In literature, GAs have been widely used in optimizing the solution to the lateral control problem of the AVS; in this regard, Son et al. [86] have proposed a genetic algorithmbased driving decision strategy (DDS) approach to determine the optimal maneuver selection by considering the real-time internal (i.e., RPM and steering angle) and external factors such as road conditions and orientation of the objects surrounding the vehicle. In another research work, Receveur et al. [87] have presented a GA-multicriteria potential field combined model-based autonomous steering control to determine the optimal global trajectory planning and local motion optimization of the vehicle simultaneously. The authors categorized the experiments into (i) potential field and (ii) GA potential Field and evaluated the performance of the proposed model in the simulated road environment. $\mathrm{Du}$ et al. [88] presented a GA-based nonlinear optimization model to determine the optimal steering angle and acceleration rate in order to enhance the maneuverability in AVs. $\mathrm{Xu}$ et al. [89] proposed GA fractional-order PID (FOPID) based model to optimize the five PID parameters (i.e., integral constant, derivative constant proportional constant, and integral and derivative order) to mitigate the integral of time by absolute value error (ITAE) to enhance the accuracy of the automated steer-by-wire (SBW) system. Zhao et al. [90] have proposed the GA-PID-based model to optimize the parameters of the lateral dynamic model of the vehicle to improve the stability of the steering control in linear and circular trajectory tracking.

It has been observed that the abovementioned proposed methods based on the genetic evolutionary method have improved the steering controller performance; these proposed methods have been validated through simulations. However, the proposed model has not been evaluated in real-time dynamic road scenarios considering different traffic environments and road terrain conditions. Besides, the main flaws of the GAs are that they cannot guarantee an optimal solution. Moreover, GAs take a long computational time and a significant amount of computing power for finding a near-optimal solution. Also, GAs are complicated 
and slower as compared to other methods and do not deal explicitly with complexity, and the tuning factor can be a challenging task in GAs. Therefore, these flaws of genetic algorithms alleviate the proficiency of the proposed models based on GAs. Furthermore, the strengths and limitations of the proposed models have been explicitly mentioned in Table 5.

(2) $H_{\infty}$ Controller. In the late $1970 \mathrm{~s}, H_{\infty}$ methods have been proposed in control theory to achieve stability in the lateral control of AVs which demonstrated significant applicability to the multivariate systems.

In this regard, Guo et al. [91] have proposed $H_{\infty}$ based fault lenient lateral controller for the four-wheel steering AVs to improve the effectiveness in the desired path tracking. The authors have also proposed a fault detection and response system to avoid any inconvenience while autonomous driving. In another research work, Khan et al. [92] have presented $H_{\infty}$ based differential steering control system (DSCS) for four-independent-wheel electric vehicle by combining the acceleration and yaw rate of the vehicle. To improve the stability control in the AVs dynamics, Cheng et al. [93] have introduced linear matrix inequality (LMI) based $H_{\infty}$ feedback steering control method of AVs. The proposed system controls the steering and brake system through direct yaw control (DYC) and the active front steering control (AFS) of the AVs. Hang et al. [94] have proposed Ho inspired direct yaw moment control (DYMC) system based steering control design for AVs to improve the efficiency in autonomous path tracking.

However, these techniques demonstrated significant applicability during validation in the test scenarios. But the matter of fact is that the $H_{\infty}$ based steering control methods involve complex mathematical structures which prejudice the efficiency of the controller in the real-time environment. Besides, these controllers do not represent the optimal results corresponding to performance measures but return optimal results concerning the ascribed cost function only. Moreover, these controllers do not cooperate with the nonlinear constraints generally occurring in real-time scenarios.

(3) Neural Network-Based Steering Control Techniques. During the last two decades, neural network-based systems have achieved remarkable milestones in the development of steering control modules of autonomous vehicles. One of the basic edges of a neural network is that these systems have the potential to learn the features automatically and are capable of predicting the possible outcome as well. Feedforward neural networks are commonly used to control the motion of self-driving vehicles.

Sharma et al. [95] have proposed a two-neural networkbased controller for self-driving vehicles to maintain the lateral and longitudinal control of the vehicle. The proposed networks predict the speed and steering position of the vehicle considering the trajectory and kinematic factors to adjust the steering wheels accordingly. In another research, Van and Kim [96] have proposed a convolutional neural network $(\mathrm{CNN})$ and fuzzy logic based fused steering angle estimation and control system for self-driving vehicles. The steering angle is predicted by processing the visual lane markings using CNN and the fuzzy logic-based inference engine has been devised to adjust the position of the steering wheels accordingly.

To improve the lateral control in the existing CNN-based steering control systems, Jhung et al. [97] have presented the simulated closed-loop feedback-based end-to-end steering control method for the self-driving vehicles. The proposed system is capable of posttraining learning through visual input and repositioning the steering wheels following the predicted steering angle. To improve the precision of the steering control in lane-keeping, Yaun et al. [98] have proposed deep-CNN (D-CNN) LSTM based steering control technique for AVs considering three driving states, that is, straight, left, and right turn. DCNN-LSTM is applied to driving state parameters constructed through a finite-statemachine (FSM) table to train the steering control system, which has been evaluated in five simulated road tracks in TORCS. Chen and Huang [99] have proposed an end-to-end learning-based steering control method to maintain the steering within the road lane. The proposed method estimates the steering angle from the road lane information which is extracted from the visual input to steer the wheels of the vehicle accordingly.

In another research work, Simmons et al. [100] have proposed an end-to-end learning approach for road lanefollowing for self-driving vehicles. The proposed system is categorized into (i) deep neural network-based lateral motion control (steering control) and (ii) convolutional neural network-based longitudinal motion control (speed control). However, dynamic steering control in a real-time environment is still a challenging driving task for selfdriving vehicles.

In another research work, El Hajjami et al. [101] have proposed a sliding mode steering controller based on a neural network to control the dynamics of the self-driving vehicles.

However, one of the main issues with neural networkbased steering control methods is that these systems require a huge amount of data to ensure accuracy in real-time applications. Moreover, the performance of these systems is based on prior knowledge, so these systems require data from every relevant aspect to ensure generalization.

The strengths and weaknesses of the proposed strategies are mentioned in Table 5.

2.2.2. Swarm Intelligence. Optimization of steering controller of self-driving cars using the swarm intelligence techniques: to remove the trial-and-error procedure, many areas in self-driving cars require solving several problems using optimization techniques [102]. While the analytical methods suffer from the curse of dimensionality and slow convergence, swarm intelligence- (SI-) based techniques can be a very coherent alternative [103]. Different techniques belonging to the SI family effectively solve complex problems from the planning to the control of the vehicle as discussed in the subsections (see Table 6). 
TABLE 5: Evolutionary-based steering control in self-driving vehicles.

\begin{tabular}{|c|c|c|c|c|c|c|}
\hline A & $\mathrm{B}$ & $\mathrm{C}$ & $\mathrm{D}$ & $\mathrm{E}$ & $\mathrm{F}$ & G \\
\hline [85] & \multirow{2}{*}{$\begin{array}{l}\text { Genetic } \\
\text { method }\end{array}$} & $\begin{array}{c}\text { GA-DDS-based } \\
\text { optimization model } \\
\text { considering internal and } \\
\text { external factors }\end{array}$ & $\begin{array}{l}\text { Steering angle, } \\
\text { kinematic parameters, } \\
\text { dynamic parameters }\end{array}$ & Sim/video & $\begin{array}{l}\text { The proposed model } \\
\text { performed } 22 \% \text { and } \\
40 \% \text { faster than MLP } \\
\text { and RF models, } \\
\text { respectively }\end{array}$ & $\begin{array}{l}\text { The proposed model has not } \\
\text { been evaluated in real-time } \\
\text { controlled or dynamic road } \\
\text { scenarios }\end{array}$ \\
\hline [88] & & $\begin{array}{l}\text { GA-FOPID-based } \\
\text { optimization model }\end{array}$ & $\begin{array}{l}\text { PID parameters, } \\
\text { integral and } \\
\text { derivative order }\end{array}$ & & $\begin{array}{c}\text { The proposed model } \\
\text { achieved an error rate } \\
\text { of } 1.8 \mathrm{rad}\end{array}$ & $\begin{array}{l}\text { Complex GA structure has } \\
\text { been utilized in the proposed } \\
\text { model which leads to } \\
\text { overshooting and performs } \\
\text { worse in undesired scenarios }\end{array}$ \\
\hline [90] & \multirow{2}{*}{$\begin{array}{l}H_{\infty} \\
\text { method }\end{array}$} & $\begin{array}{l}\text { Presented } H_{\infty} \text {-based fault } \\
\text { lenient lateral controller for } \\
\text { the four-wheel steering } \\
\text { AVs to improve the } \\
\text { effectiveness }\end{array}$ & $\begin{array}{l}\text { Steering angle, } \\
\text { cornering stiffness, } \\
\text { slip angles, kinematic/ } \\
\text { dynamic parameters }\end{array}$ & Simulation & $\begin{array}{l}\text { Achieved lateral error } \\
\text { and angular error } \\
0.08 \mathrm{~m} \text { and } 0.14 \mathrm{~m} \text {, } \\
\text { respectively }\end{array}$ & $\begin{array}{l}\text { Simulations carried out with } \\
\text { low constant vehicle speed }\end{array}$ \\
\hline [92] & & $\begin{array}{l}\text { Proposed } H_{\infty} \text { (DYC) } \\
\text { inspired system-based } \\
\text { steering control design for } \\
\text { AVs to improve the } \\
\text { efficiency in autonomous } \\
\text { path tracking }\end{array}$ & $\begin{array}{l}\text { Vehicle mass, steering } \\
\text { angle, cornering } \\
\text { stiffness, slip angles, } \\
\text { dynamic and } \\
\text { kinematic parameters }\end{array}$ & & $\begin{array}{l}\text { Decreased the side } \\
\text { slip angle and path } \\
\text { tracking error } \\
\text { effectively }\end{array}$ & $\begin{array}{l}\text { Any practical implementation } \\
\text { in the real world has not been } \\
\text { performed }\end{array}$ \\
\hline [93] & \multirow{2}{*}{$\begin{array}{c}\text { Neural } \\
\text { networks }\end{array}$} & $\begin{array}{l}\text { Presented two-neural } \\
\text { networks-based controller } \\
\text { for the self-driving }\end{array}$ & $\begin{array}{l}\text { Lane marking, RPM, } \\
\text { steering angle }\end{array}$ & TORCS & $\begin{array}{l}\text { The proposed system } \\
\text { achieved satisfactory } \\
\text { accuracy in the } \\
\text { defined simulated } \\
\text { track }\end{array}$ & $\begin{array}{l}\text { The proposed system has been } \\
\text { evaluated on the static test } \\
\text { track with a certain speed and } \\
\text { velocity }\end{array}$ \\
\hline [94] & & $\begin{array}{l}\text { Fuzzy logic-deep steering } \\
\text { neural network-based } \\
\text { steering control system for } \\
\text { self-driving car }\end{array}$ & $\begin{array}{l}\text { Lane markings, } \\
\text { steering angle, and } \\
\text { velocity }\end{array}$ & MATLAB & $\begin{array}{l}\text { The proposed system } \\
\text { achieved } 7.3 \text { MSE in } \\
\text { the Udacity challenge } \\
\text { environment }\end{array}$ & $\begin{array}{l}\text { The proposed algorithm has } \\
\text { not been tested in the dense } \\
\text { traffic scenarios }\end{array}$ \\
\hline
\end{tabular}

A: reference, B: technique, C: contribution, D: considered parameters, E: testbed, F: strengths, and G: limitations.

(1) PSO-Based MPC Techniques for Steering Control of SelfDriving Cars. MPC is the most advanced technology in the industry due to its tolerance to numerous control systems [104]. This technique can work in compliance with the imposed constraints as well as its compatibility with different types of equipment. However, in the areas involving fast dynamics and real-time decision-making such as robotics and automation, its application has not been noticed due to the heavy computation needed to solve nonlinear optimization problems. This technique involves taking an optimized control action at each sampling instant. Hence, swarm-based optimization techniques have been used to solve the problems arising in the nonlinear MPC. Steering control is the most common maneuver performed by the driver. MPC with PSO has proven to be effective in steering control of an autonomous vehicle. An approach has been proposed for vehicle control using MPC [105]. To overcome the nonlinearity of the MPC, PSO has been used which made it efficient in reasonable computation time. An optimal path planning technique based on MPC has been used in the design of the kinematic controller [106]. To realize path optimization, PSO is employed to acquire a smoother path which helps to avoid obstacle meeting curvature constraints. In [107], a control strategy has been proposed to optimize the steering performance of a vehicle. For this purpose, they have proposed a PSO-based
nonlinear-MPC (NMPC) technique to calculate the yaw moment of the vehicle in the upper controller. It has been noticed that the application of NMPC has begun in the fastdynamic response systems like the trajectory planning of the vehicle which depends on the optimal steering and velocity control. To solve this problem, quantum PSO (QPSO) has been used in [108] which helps to find a globally optimal solution and avoid falling into the local optima. Thus, NMPC with QPSO has been employed in the dynamic steering control of the vehicle. Hence, the incorporation of PSO in the MPC helps optimize the nonlinear optimization problem of steering control in less computation time.

(2) SI-Based PID Controllers. PID controller has been used in many industries to control and regulate the process variables. The researchers have carried out different studies on automatic steering control of the vehicle using the PID controller. However, the PID controller is more prone to failure in case of sudden changes in the system variable. Using classical techniques for this purpose is a monotonous job and more often results in inaccurate system response [109]. This hindrance can be controlled by fine-tuning of the steering control parameters using heuristic optimization techniques showing superiority over classical tuning methods. The PID controller has 
TABLE 6: Swarm Intelligence-based steering control optimization in self-driving vehicles.

\begin{tabular}{cccccc}
\hline A & B & C & D & E & F \\
\hline $\begin{array}{c}\text { PSO has been used to } \\
\text { overcome the nonlinearity } \\
\text { in the MPC }\end{array}$ & $\begin{array}{c}\text { Kinematic parameters, } \\
\text { dynamic parameters }\end{array}$ & Simulation & $\begin{array}{c}\text { Optimized MPC, reduced the } \\
\text { computation time }\end{array}$ & N/A \\
\hline
\end{tabular}

Proposed an optimal guidance scheme (improved

[106] PSO) based on MPC in the design of the kinematics controller
Kinematics parameter,

curvature of the path, Simulation Helped to avoid obstacles rotation transformation
This approach can also be extended to path planning and following other unmanned vehicles

\begin{tabular}{ccc}
\hline $\begin{array}{c}\text { Proposed a PSO-based } \\
\text { nonlinear-MPC (NMPC) } \\
\text { technique to calculate the } \\
\text { yaw moment of the vehicle }\end{array}$ & $\begin{array}{c}\text { Kinematic parameters, Simualtion } \\
\text { dynamic parameters }\end{array}$ & $\begin{array}{c}\text { Optimized the steering } \\
\text { performance of a vehicle }\end{array}$ \\
\hline $\begin{array}{c}\text { NMPC with QPSO has been } \\
\text { proposed for the dynamic } \\
\text { steering control of the } \\
\text { vehicle }\end{array}$ & $\begin{array}{c}\text { Kinematic parameters, } \\
\text { dynamic parameters, MATLAB } \\
\text { wheel steering angle. }\end{array}$ & $\begin{array}{c}\text { The concurrent design greatly } \\
\text { improved the speed of } \\
\text { optimization }\end{array}$ \\
\hline
\end{tabular}

Developed a model-free PID controller with derivative

[109] filter (PDF) parameter tuning method by using PSO
Dynamic parameter Simulation

Yielded a good transient response with no steady-state error

The effectiveness of the proposed method is only verified under the singlelane manoeuvre

Deviation has been noticed in the reference trajectory

The higher the number of particles, the longer algorithm takes to complete its iteration but the result sometimes is not even better than the previous run

The control algorithm could not search more than one path and chose the one among them in case of obstacles in the road dynamic parameters, vehicle mass, radius MATLAB The controller optimally tuned

Discussed how the PID

[110] controller is tuned to control angular and linear motion wheelbase selecting the most appropriate values of the PID

This research needs to be

Kinematic parameters,

This paper compares five kinds of tuning methods of a

[111] parameter for the PID controller, such as FA, PSO, ACO, BA, and ICA dynamic parameters, vehicle mass, radius Simulation Provided correct results as wheelbase compared to the PID controller extended to check its performance on real vehicle conditions

Other methods to tune the Proposed an optimized

[113] design of FOPID using PSO and GA

Kinematic and dynamic parameters

MATLAB Imp

Improved the steering control of the AV parameters of a FOPID

controller which could be tested on an actual system

Only theoretical study is carried out
[115] control parameters of the higher-order SMC using PSO

A novel approach for fourwheel steer and drive vehicle

[82] has been presented which helps to track a path using SMC

Devised a path tracking technique for automatic

[116] steering control of a vehicle based on Stanley controller
QPSO is employed to optimize the track control. A

[117] steering control model has been devised by using adaptive parallel series
Steering wheel angle, kinematic and dynamic parameters, cornering stiffness

The dynamic variables obtained MATLAB by SMC with PSO are better than the results obtained by SMC

\begin{tabular}{|c|c|c|c|}
\hline $\begin{array}{l}\text { Kinematic parameters, } \\
\text { initial heading error } \theta\end{array}$ & Simulation & $\begin{array}{l}\text { The proposed method showed } \\
\text { the accurate path followed and } \\
\text { accurate reference velocity and } \\
\text { acceleration profile followed } \\
\text { under varying terrain conditions }\end{array}$ & $\begin{array}{l}\text { Experiments will be carried } \\
\text { out to verify the validity of } \\
\text { the proposed method }\end{array}$ \\
\hline $\begin{array}{c}\text { Kinematics and } \\
\text { dynamic parameters }\end{array}$ & Simulation & $\begin{array}{l}\text { In general, both modified } \\
\text { controllers performed well in } \\
\text { guiding the vehicle to follow the } \\
\text { intended path }\end{array}$ & $\begin{array}{l}\text { The control parameters still } \\
\text { need to be optimized for } \\
\text { better steering control of the } \\
\text { vehicle }\end{array}$ \\
\hline $\begin{array}{c}\text { Dynamic parameters, } \\
\text { steer angle }\end{array}$ & N/A & $\begin{array}{l}\text { The tracking control is effectively } \\
\text { achieved in the semiautonomous } \\
\text { driver assistance system }\end{array}$ & $\begin{array}{l}\text { Needs to be applied to the } \\
\text { real system, such as senior } \\
\text { vehicles and autonomous } \\
\text { vehicles }\end{array}$ \\
\hline
\end{tabular}

A: authors, B: contribution, C: considered parameters, D: testbed, E: strengths, and F: limitations. 
been tuned using PSO in [110] which helps to control the linear as well as the angular motion of the car by selecting the most appropriate values of the PID controller. In [109], the authors have proposed a model-free derivative filter PID and tuned its control parameters using PSO. The development of the proposed mechanism is used in the steering control of autonomous vehicles. Furthermore, the work in [111] has provided a detailed comparison for the active steering control of an autonomous vehicle using a PID controller. They have tuned the PID controller using five types of SI techniques which include PSO, firefly algorithm (FA), ant colony optimization (ACO), imperialist competitive algorithm (ICA), and bat algorithm (BA). The tuning of the PID controller using the SI-based techniques provided more accurate results as compared to the PID controller. Furthermore, to steer the vehicle on the predefined path, fractional-order PID (FOPID) is utilized in [112]. To optimally tune the parameters of FOPID, the author has employed PSO which in turn helps to minimize the cost function used in the algorithm. In another study [113], the authors have proposed an optimized design of FOPID where the controller has been optimized using PSO and the genetic algorithm (GA) to improve the steering control of the autonomous underwater vehicle.

(3) Optimization of Sliding Mode Control Parameters Using SI-Based Techniques for Steering Control of Autonomous Vehicles. Sliding mode control (SMC) is a widely acknowledged methodology which handles uncertainties in control systems [114]. The steering control systems are characterized by hard nonlinearities; therefore, SMC perfectly fits to cope with such systems. Many studies have integrated the SI-based techniques to optimize the parameters of the steering control systems using SMC which helps to increase the robustness of the system. A higher-order SMC has been used to develop a strategy for steering control of an autonomous vehicle [115]. For this purpose, a supertwisting algorithm is employed and more particularly the control parameters of the higherorder SMC have been optimized using PSO. A novel approach for four-wheel steer and drive vehicle has been presented which helps to track a path using SMC [22]. The proposed technique determines the steering angles using a combination of kinematic model and SMC and determines the drive torque using a combination of PSO and dynamic model.

(4) Other SI-Based Techniques to Optimize Steering Control Parameters. A path tracking technique is devised for automatic steering control of a vehicle based on the Stanley controller [116]. The optimum set of control parameters of the controller are acquired using PSO. Though the efficiency of the controller solely depends on the fine-tuning of the parameters for any given path, then control parameters still need to be optimized. Basic research is conducted in [117] for the steering support of driver assistance systems for senior drivers. To search the optimal feedback for optimized track control and to reduce the convergence quantum, PSO is employed. A steering control model has been devised by using adaptive parallel series in [118]. The gains of the proposed model are optimized using PSO to avoid the windup problem and help to achieve fast convergence. However, they could incorporate the parameters of surge and sway modes of other degrees of freedom. We encourage the researchers to apply these methods to more realistic and complex models with more nonlinearities and evaluate their performance by applying external disturbance.

2.2.3. Physics-Chemistry-Based Method. All heuristic algorithms are not bioinspired except physics and chemistry inpired steering control systems. Many algorithms have been developed by imitating some physical and/or chemical laws that are not biologically based, like electrical charges, gravity, and river systems. As various natural structures apply to this group, they may also be divided into other needless subcategories. Although physics and chemistry are two separate subjects, splitting this subcategory in more depth into physical and chemistry algorithms is not useful. Hence, many fundamental laws of both subjects are the same, so we can simply group them as physics-chemistry-based algorithms.

In literature, physics-chemistry-based Big Bang-Big Crunch and harmony search method played a vital role in the optimization of the steering controllers [119]. Big BangBig Crunch (BB-BC) is the physics-chemistry-based evolutionary method, which was proposed in 2005 [120]. BB-BC is based on the hypothetical theorem of creation and destruction of the universe; this method provides better optimization results while converging to the optimal solution set with a high convergence speed, lower computational time, and low computation cost [121].

$\mathrm{BB}-\mathrm{BC}$ have incredible abilities due to which Kumbasar and Hagras [122] presented the novel application of the BigBang-Big crunch approach for the optimization of the parameters of the interval type-2 fuzzy PID (IT2-FPID) controllers in a cascade steering control structure for the PIONEER 3DX AV. Besides, cascade control architecture has been proposed to resolve the control problem due to the uncertainties of the AV, caused by the internal dynamics and/or feedback sensors of the controlled system. The proposed approach has been validated through simulations and real-world experiments; hence the results have shown that the proposed controller improved the controller performance in the presence of the external distortion and uncertainties in the real world. However, catering to the external disturbances and uncertainties depends on the use of different methodologies not on the number of the parameter; hence, the extra parameter used in the structure only increased the complexity of the control system of the AV.

Another physics-chemistry-inspired evolutionary method named the harmony search method was introduced by Geem et al. [123] in 2001. Besides, the function of the harmony improvisation and its engineering application is based on the musical phenomena. In the literature, it has been observed that the harmony search (HS) method is used to optimize the different optimization problems by 
considering the rules, that is, Pitch Adjusting rules, random selecting, and harmony memory [124].

HS method has many advantages such as less adjustable parameters and easy implementation and has the ability of quick convergence [125]. However, the method of the HS has some defects such as slow convergence speed and premature convergence. Sharma et al. [126] have presented an adaptive fuzzy controller based on the combination of the harmony search method and Lyapunov theory for controlling the motion of the vision-based AVs. Moreover, dynamic harmony search (Dyas) has been used to design two self-adaptive fuzzy controllers that are responsible for the movement of the AV in the $X, Y$ direction. Finally, the proposed method has been implemented in both simulation and real-life experiments. Hence, the results demonstrated that the structure and parameters of the proposed controller have been optimized and ensured the stability of the controller and provide a high degree of automation in the controller design process. However, one of the main drawbacks of the proposed method is that all the candidate solutions to be evolved as a fixed-length vector using an HS method and may have a decreased rate of convergence. Hence, it would be interesting to solve a similar problem by considering the variable-length vectors in the harmony memory and perform statistical analysis of the solution for identical problems using both fixed and variable-length vectors. In another research, $\mathrm{He}$ et al. [127] proposed the harmony search genetic method to tune the parameters of the PID controller of the mechanical arm controller. The mechanical arm is a nonlinear control system with a number of multivariables and has a complicated structure and uncertain parameters. Moreover, the authors have considered the harmony search and harmony adjustment to operate the initial data of the proposed method to select the appropriate data for the control system. The performance of the proposed method has been verified through simulation; however, any practical implementation of the proposed method has not been performed in a real-world environment.

\section{Research Question}

3.1. Lack of Vehicle Kinematic and Dynamic Modeling in Geometric Steering Controllers. The existing geometric-based steering control methods, that is, pure pursuit [34], Stanley [37], and vector pursuit [38], estimate the orientation of the vehicle through look-ahead point while ignoring the vehicle kinematics, that is, acceleration and velocity. Besides, these methodologies do not present any scheme to cater to the dynamic forces, that is, linear and angular momentum, torque, side slip angle, and friction acting on the steering wheels which significantly influence the accuracy of the lateral motion of the vehicle. In the future, it would be interesting to introduce the deterministic methodologies for dynamic force measurement, acting on the steering wheels of the vehicle.

3.2. External Disturbance in Steering Control System. One of the main limitations of the steering control techniques presented by the Park et al. [31], Andersen et al. [32],
Zhao et al. [59], Wang et al. [45], and Sun et al. [47] is that these techniques do not include any module to cater with the latency and additive bias occurred in the assessment of the steering angle of the vehicle. Moreover, these techniques also neglected the crucial steering parameters, that is, slip phenomena, suspension movement, and dynamics of the vehicle. Consequently, these limitations lead toward a higher tendency for oscillation which considerably prejudices the effectiveness of these controllers in real-time dynamic road conditions. These limitations are an indication towards the need for realtime external disturbance detection and response system to improve the motion control of self-driving vehicles.

3.3. Lack of Customized Steering Control. The discussed steering control techniques are proposed for standard steering systems of the vehicles, whereas the automobile industry is moving towards the development of customized steering control systems for the autonomous vehicle to be controlled through an autopilot. However, very scant literature is contributed by the research community regarding the customization of steering systems. In this regard, a huge research gap is found in the development of steering control systems for customized steering systems of autonomous vehicles. There is a need for further improvement in the customization of electric steering systems to make them reliable for self-driving vehicles.

3.4. Lack of Stability in Feedback-Based Steering Controllers. It is noted from the abovementioned MPC- and PID-based feedback steering control methods that these systems comprise complex mathematical structures which require precise input to maintain accuracy, whereas the performance of the fuzzy logic-based feedback steering controllers is prejudiced with the increase in the fuzzy rules in the inference engine. Consequently, these limitations raise latency and instability issues in the real-time road environment. It would be interesting to explore the abovementioned algorithms to improve the ratio of proportion and derivation in order to improve stability in real-time steering control systems in self-driving vehicles.

3.5. Lack of Benchmark Dataset for Neural Networks-Based Steering Control Systems. With the evolution in the field of artificial intelligence, computer vision-based steering control systems have demonstrated groundbreaking applicability in the controlled environments. But the matter of fact is that these methodologies require a huge amount of data to maintain accuracy. Until recently, no benchmark dataset containing diverse road terrain images along with the corresponding steering angles is available to train and evaluate effective neural network-based steering control systems for autonomous vehicles. Moreover, these methods require visual input to extract the road lane markings which significantly influence the different luminous conditions. However, these issues have not been catered to the existing steering control 
techniques. In this regard, there is a need for generalized benchmark datasets to improve the accuracy of steering control systems in real-time dynamic road conditions.

3.6. Lack of Validation Techniques for the Optimization Methods Used over the Steering Control System. In the literature, various optimization techniques have been employed to fine-tune the output of the steering control systems. References [86-90] have utilized the genetic algorithms to optimize the kinematical and dynamic model of the steering controller of the vehicle. Besides, references [22, 103-116] have used swarm optimization techniques to optimize the parameters of the steering control methods. However, the genetic algorithm-based optimization techniques cannot be utilized in the realtime steering control system because of their complex structure which raises latency issues in the dynamic road conditions. Moreover, researchers have not introduced agent-based modeling (ABM) for these steering control systems to validate the effects of the utilized optimization techniques in the parameter selection and fine-tuning process. Besides, the ABM-based validation methods can play a significant role in the modeling of the human driver behavior to prioritize the vehicle parameters following the real-time road conditions [8, 10, 128-133]. In this regard, it would be interesting to introduce a validation mechanism for the optimization of steering control systems.

3.7. Lack of Practical Implementation of Steering Control Systems. From the tables [2, 4-7], it can be seen that $90 \%$ of the proposed steering control techniques are based on either the theoretical models or simulations which do not demonstrate the same applicability in the real-time road conditions. One of the main problems in the practical implementation of these theoretical models is that these systems are based on highly complex mathematical models that do not perform well in the real-time road conditions [133-135]. Moreover, these models do not consider the dynamic factors of real-time environments, which greatly influence the motion of the autonomous vehicles. In this regard, there is a need for practical research contributions from academia to fill this gap.

\section{Conclusion}

In this paper, we presented a critical review of the existing steering control techniques for the self-driving vehicles of different autonomy levels. A novel taxonomy of the steering control methods has been proposed to demonstrate an overview of the evolution in the steering control mechanisms of the self-driving vehicles. Based on the thorough analysis, the key challenges and the research gap in the existing steering control techniques have been highlighted. Lastly, the possible solutions to the identified research gaps have been discussed to improve the effectiveness of the automated steering control systems of the self-driving vehicles.
The following abbreviations are used in this manuscript.

\section{Abbreviations}

AVs: $\quad$ Autonomous vehicles

SAE: $\quad$ Society of Automotive Engineer

HPS: $\quad$ Hydraulic power steering

PP: $\quad$ Pure pursuit

PI: $\quad$ Integral derivation

DARPA: Defense Advanced Research Projects Agency

NTV: $\quad$ Navigation test vehicle

Lad: $\quad$ Look-ahead distance

RMS: $\quad$ Root mean square

MPC: $\quad$ Model predictive control

LQR: Linear-quadratic regulator

MIMO: Multiinput multioutput

LQG: Linear-quadratic Gaussian

AHDV: Articulated heavy-duty vehicle

RLQR: Robust linear-quadratic regulator

FSM: $\quad$ Finite-state machine

4WS: $\quad$ Four-wheel steering

2-DOF: Two-degree-of-freedom

3-DOF: Three-degree-of-freedom

CNN: Conventional neural network

BP: Backpropagation

FL: $\quad$ Functional link

DMPC: $\quad$ Distributed model predictive control

PID: $\quad$ Proportional-integral derivative

FL: $\quad$ Fuzzy logic

DP: $\quad$ Dynamic programming

SMC: $\quad$ Sliding mode control

4WIS EV: Four-wheel-independent-steering electric vehicle

PWM: $\quad$ Pulse width modulation

GPS: Global Positioning System

ADP: $\quad$ Adaptive dynamic programming

NDP: $\quad$ Neural dynamic programming

GA: $\quad$ Genetic algorithm

PSO: $\quad$ Particle swarm optimization

NASTSM: Nested adaptive supertwisting sliding mode

EAs: $\quad$ Evolutionary algorithms

IMU: Inertial measurement unit

DDS: $\quad$ Driving decision strategy

SBW: $\quad$ Steer-by-wire

FOPID: Fractional-order PID

ITAE: Integral of time by absolute value error

DSCS: Differential steering control system

DYC: Direct yaw control

LMI: Linear matrix inequality

AFS: $\quad$ Active front steering control

DYMC: Direct yaw moment control

RPM: $\quad$ Revolutions per minute

TORCS: The open racing car simulator

FLSC: $\quad$ Fuzzy logic steering control

ICR: Instant centre of rotation

T2FC: $\quad$ Type-2 fuzzy controller

QPSO: Quantum particle swarm optimization

NMPC: Nonlinear model predictive control

ACO: Ant colony optimization 
FA: $\quad$ Firefly algorithm

ICA: Imperialist competitive algorithm

BB-BC: Big Bang-Big Crunch

ITS- Interval type-2 fuzzy PID

FPID:

HS: Harmony search

CARLA: Computer Aided Related Language Adaptation

ABM: $\quad$ Agent-based modeling.

\section{Data Availability}

The data used to support the findings of this study are included within the article.

\section{Conflicts of Interest}

The authors declare no conflicts of interest.

\section{Acknowledgments}

This study was supported by the BK21 FOUR project (AIdriven Convergence Software Education Research Program) funded by the Ministry of Education, School of Computer Science and Engineering, Kyungpook National University, Korea (4199990214394). This work was also supported by the National Research Foundation of Korea (NRF) grant funded by the Korea Government (MSIT) (no. 2019R1F1A1042721).

\section{References}

[1] "Road traffic injuries," 2020, https://www.who.int/newsroom/fact-sheets/detail/road-traffic-injuries.

[2] Y. Li, D. Wu, J. Lee, M. Yang, and Y. Shi, "Analysis of the transition condition of rear-end collisions using time-tocollision index and vehicle trajectory data," Accident Analysis \& Prevention, vol. 144, Article ID 105676, 2020.

[3] E. Dabbour, O. Dabbour, and A. A. Martinez, "Temporal stability of the factors related to the severity of drivers' injuries in rear-end collisions," Accident Analysis \& Prevention, vol. 142, Article ID 105562, 2020.

[4] K. Jetto, Z. Tahiri, A. Benyoussef, and A. El Kenz, "Cognitive anticipation cellular automata model: an attempt to understand the relation between the traffic states and rear-end collisions," Accident Analysis \& Prevention, vol. 142, Article ID 105507, 2020.

[5] J. I. Castillo-Manzano, M. Castro-Nuño, L. López-Valpuesta, and F. V. Vassallo, "An assessment of road traffic accidents in Spain: the role of tourism," Current Issues in Tourism, vol. 23, no. 6, pp. 654-658, 2020.

[6] K. Reeves, J. S. Chandan, and S. Bandyopadhyay, "Using statistical modelling to analyze risk factors for severe and fatal road traffic accidents," International Journal of Injury Control and Safety Promotion, vol. 26, no. 4, pp. 364-371, 2019.

[7] D. Wang, Q. Liu, L. Ma, Y. Zhang, and H. Cong, "Road traffic accident severity analysis: a census-based study in China," Journal of Safety Research, vol. 70, pp. 135-147, 2019.

[8] S. Khadim, F. Riaz, S. Jabbar, S. Khalid, and M. Aloqaily, "A non-cooperative rear-end collision avoidance scheme for non-connected and heterogeneous environment," Computer Communications, vol. 150, pp. 828-840, 2020.
[9] A. A. Minhas, S. Jabbar, M. Farhan, and M. N. u. Islam, "Smart methodology for safe life on roads with active drivers based on real-time risk and behavioral monitoring," Journal of Ambient Intelligence and Humanized Computing, 2019.

[10] F. Riaz, S. Khadim, R. Rauf, M. Ahmad, S. Jabbar, and J. Chaudhry, "A validated fuzzy logic inspired driver distraction evaluation system for road safety using artificial human driver emotion," Computer Networks, vol. 143, pp. 62-73, 2018.

[11] Kaleem Razzaq Malik, M. Ahmad, S. Khalid, H. Ahmad, F. Al-Turjman, and S. Jabbar, "Image and command hybrid model for vehicle control using Internet of Vehicles," Transactions on Emerging Telecommunications Technologies, vol. 31, no. 5, p. e3774, 2020.

[12] "SAE international releases updated visual chart for its levels of driving automation standard for self-driving vehicles," 2018, https://www.sae.org/news/press-room/2018/12/saeinternational-releases-updated-visual-chart-for-its-\%E2\% $80 \% 9$ Clevels-of-driving-automation $\% \mathrm{E} 2 \% 80 \% 9 \mathrm{D}$-standardfor-self-driving-vehicles.

[13] M. Anderson, "The road ahead for self-driving cars: the AV industry has had to reset expectations, as it shifts its focus to level 4 autonomy," IEEE Spectrum, vol. 57, no. 5, pp. 8-9, 2020.

[14] S. Karnouskos, "The role of utilitarianism, self-safety, and technology in the acceptance of self-driving cars," Cognition, Technology \& Work, pp. 1-9, 2020.

[15] M. A. Cusumano, "Self-driving vehicle technology: progress and promises," Communications of the ACM, vol. 63, no. 10, pp. 20-22, 2020.

[16] "Dubai's autonomous transportation strategy," 2020, https:// www.dubaifuture.gov.ae/our-initiatives/dubaisautonomous-transportation-strategy/.

[17] A. Friedrich, "By 2030, one in 10 vehicles will be self-driving globally,” 2020, https://www.statista.com/press/p/ autonomous_cars_2020/.

[18] J. Ni, Y. Chen, Y. Chen, J. Zhu, D. Ali, and W. Cao, "A survey on theories and applications for self-driving cars based on deep learning methods," Applied Sciences, vol. 10, no. 8, p. 2749, 2020.

[19] J. Borenstein, J. R. Herkert, and K. W. Miller, "Self-driving cars and engineering ethics: the need for a system level analysis," Science and Engineering Ethics, vol. 25, no. 2, pp. 383-398, 2019.

[20] C. Häne, L. Heng, G. H. Lee et al., “3D visual perception for self-driving cars using a multi-camera system: calibration, mapping, localization, and obstacle detection," Image and Vision Computing, vol. 68, pp. 14-27, 2017.

[21] G. Dixon, P. S. Hart, C. Clarke, N. H. O’Donnell, and J. Hmielowski, "What drives support for self-driving car technology in the United States?" Journal of Risk Research, vol. 23, no. 3, pp. 275-287, 2020.

[22] P. Dai, J. Taghia, S. Lam, and J. Katupitiya, "Integration of sliding mode based steering control and PSO based drive force control for a 4WS4WD vehicle," Autonomous Robots, vol. 42, no. 3, pp. 553-568, 2018.

[23] C. Hu, Y. Qin, H. Cao et al., "Lane keeping of autonomous vehicles based on differential steering with adaptive multivariable super-twisting control," Mechanical Systems and Signal Processing, vol. 125, pp. 330-346, 2019.

[24] Y. Chen, Y. Shan, L. Chen, K. Huang, and D. Cao, "Optimization of pure pursuit controller based on PID controller and low-pass filter," in Proceedings of the 2018 21st 
International Conference on Intelligent Transportation Systems (ITSC), Maui, HI, USA, 2018.

[25] M. Park and W. Han, "Corresponding author 2," in Proceedings of the 2014 International Conference on Control, Automation and Systems, Seoul, Republic of Korea, 2014.

[26] A. A. Kesarkar and N. Selvaganesan, "Tuning of optimal fractional-order PID controller using an artificial bee colony algorithm," Systems Science \& Control Engineering, vol. 3, no. 1, pp. 99-105, 2015.

[27] N. Siddique and H. Adeli, "Nature inspired computing: an overview and some future directions," Cognitive Computation, vol. 7, no. 6, pp. 706-714, 2015.

[28] X. S. Yang and Y. X. Zhao, Nature-Inspired Computation in Navigation and Routing Problems: Methods, Methods and Applications, Springer, Berlin, Germany, 2020.

[29] X. S. Yang and X. S. He, Mathematical Foundations of Nature-Inspired Methods, Springer International Publishing, Berlin, Germany, 2019.

[30] M. Cibooglu and M. Turan, "Mertcan Cibooglu, \$4," vol. 8, pp. 583-588, 2017.

[31] M. Park, S. Lee, and W. Han, "Development of steering control system for autonomous vehicle using geometrybased path tracking algorithm," ETRI Journal, vol. 37, no. 3, pp. 617-625, 2015.

[32] H. Andersen, Z. J. Chong, Y. H. Eng, S. Pendleton, and M. H. Ang, "Geometric path tracking method for autonomous driving in pedestrian environment," in Proceedings of the 2016 IEEE International Conference on Advanced Intelligent Mechatronics (AIM), Banff, Canada, 2016.

[33] G. M. Hoffmann, C. J. Tomlin, M. Montemerlo, and S. Thrun, "Autonomous automobile trajectory tracking for off-road driving: controller design, experimental validation and racing," in Proceedings of the 2007 American Control Conference, New York, NY, USA, 2007.

[34] "Reviewed work(s): a treatise on the theory of screws by Robert Stawell Ball review," Science, vol. 12, no. 313, pp. 1001-1003, 2020.

[35] R. Wallace, A. Stentz, C. E. Thorpe, H. Maravec, W. Whittaker, and T. Kanade, "First results in robot road following," in Proceedings of the 1985 IJCAI, Los Angeles, CA, USA, 1985.

[36] H. Li, J. Luo, S. Yan, M. Zhu, Q. Hu, and Z. Liu, "Research on parking control of bus based on improved pure pursuit algorithms," in Proceedings of the 2019 18th International Symposium on Distributed Computing and Applications for Business Engineering and Science (DCABES), Wuhan, China, 2019.

[37] Y. Shan, W. Yang, C. Chen, J. Zhou, L. Zheng, and B. Li, "CFpursuit: a pursuit method with a clothoid fitting and a fuzzy controller for autonomous vehicles," International Journal of Advanced Robotic Systems, vol. 12, 2015.

[38] J. M. Snider, Automatic Steering Methods for Autonomous Automobile Path Tracking, Carnegie Mellon University, Pittsburgh, PA, USA, 2009.

[39] T. K. Yeu, S. J. Park, S. Hong, S. Hong, H. W. Kim, and J. S. Choi, "Path tracking using vector pursuit algorithm for tracked vehicles driving on the soft cohesive soil," in Proceedings of the 2006 SICE-ICASE International Joint Conference, pp. 2781-2786, Busan, Korea, October 2006.

[40] S. Bacha, R. Saadi, M. Y. Ayad, A. Aboubou, and M. Bahri, "A review on vehicle modeling and control technics used for autonomous vehicle path following," in Proceedings of the 2017 International Conference on Green Energy Conversion Systems (GECS), Hammamet, Tunisia, 2017.
[41] Y. Yan, K. Geng, S. Liu, and Y. Ren, "A new path tracking algorithm for four-wheel differential steering," in Proceedings of the 2019 Chinese Control Decision Conference, Nanchang, China, 2019.

[42] J. Wit, C. D. Crane, and D. Armstrong, "Autonomous ground vehicle path tracking," Journal of Robotic Systems, vol. 21, no. 8, pp. 439-449, 2004.

[43] S. Binitha and S. S. Sathya, "A survey of bio inspired optimization algorithms," International Journal of Soft Computing and Engineering, vol. 2, no. 2, pp. 137-151, 2012.

[44] H. Nam, W. Choi, and C. Ahn, "Model predictive control for evasive steering of an autonomous vehicle," International Journal of Automotive Technology, vol. 20, no. 5, pp. 1033 1042, 2019.

[45] H. Wang, X. Liu, and Q. An, "Path tracking control for autonomous vehicles based on an improved MPC," IEEE Access, vol. 7, Article ID 161064, 2019.

[46] J. Cai, H. Jiang, L. Chen, J. Liu, Y. Cai, and J. Wang, "Implementation and development of a trajectory tracking control system for intelligent vehicle," Journal of Intelligent \& Robotic Systems, vol. 94, no. 1, pp. 251-264, 2019.

[47] C. Sun, X. Zhang, L. Xi, and Y. Tian, "Design of a pathtracking steering controller for autonomous vehicles," Energies, vol. 11, no. 6, p. 1451, 2018.

[48] C. Sun, X. Zhang, Q. Zhou, and Y. Tian, “A model predictive controller with switched tracking error for autonomous vehicle path tracking," IEEE Access, vol. 7, no. c, pp. 53103-53114, 2019.

[49] K. Lee, S. Jeon, H. Kim, and D. Kum, "Optimal path tracking control of autonomous vehicle: adaptive full-state linear quadratic Gaussian (LQG) control," IEEE Access, vol. 7, pp. 109120-109133, 2019.

[50] F. M. Barbosa, L. B. Marcos, M. M. da Silva, M. H. Terra, and V. Grassi, "Robust path-following control for articulated heavy-duty vehicles," Control Engineering Practice, vol. 85, pp. 246-256, 2019.

[51] K.-i. Kim, H. Guan, B. Wang, R. Guo, and F. Liang, "Active steering control strategy for articulated vehicles," Frontiers of Information Technology \& Electronic Engineering, vol. 17, no. 6, pp. 576-586, 2016.

[52] Z. Jiang and B. Xiao, "LQR optimal control research for fourwheel steering forklift based-on state feedback," Journal of Mechanical Science and Technology, vol. 32, no. 6, pp. 2789-2801, 2018.

[53] Y. Saito, M. Itoh, and T. Inagaki, "Dual control theoretic driver assistance," Transactions of the Society of Instrument and Control Engineers, vol. 50, no. 6, pp. 461-470, 2014.

[54] X. Na and D. J. Cole, "Modelling of a human driver s interaction with vehicle automated steering using cooperative game theory," IEEE/CAA Journal of Automatica Sinica, vol. 6, no. 5, pp. 1095-1107, 2019.

[55] X. Na and D. J. Cole, "Game-theoretic modeling of the steering interaction between a human driver and a vehicle collision avoidance controller," IEEE Transactions on $\mathrm{Hu}$ man-Machine Systems, vol. 45, no. 1, pp. 25-38, 2015.

[56] T. Zhu, X. Jin, G. Yin, J. Liang, Z. Ren, and Y. Shi, "Coordinated control for active 4WS vehicle based on linear quadratic differential game," in Proceedings of the 2019 Chinese Control and Decision Conference (CCDC), Nanchang, China, 2019.

[57] M. Li, X. Song, H. Cao et al., "Shared control with a novel dynamic authority allocation strategy based on game theory and driving safety field," Mechanical Systems and Signal Processing, vol. 124, pp. 199-216, 2019. 
[58] A. Baskaran, A. Talebpour, and S. Bhattacharyya, "End-toend drive by-wire PID lateral control of an autonomous vehicle," in Proceedings of the 2019 Future Technologies Conference, San Francisco, CA, USA, 2019.

[59] P. Zhao, J. Chen, Y. Song, X. Tao, T. Xu, and T. Mei, “Design of a control system for an autonomous vehicle based on adaptive-PID," International Journal of Advanced Robotic Systems, vol. 9, pp. 1-11, 2012.

[60] J. Yin, D. Zhu, J. Liao, G. Zhu, Y. Wang, and S. Zhang, "Automatic steering control algorithm based on compound fuzzy PID for rice transplanter," Applied Sciences, vol. 9, no. 13, p. 2666, 2019.

[61] X. Chen, Q. Bao, and B. Zhang, "Research on 4WIS electric vehicle path tracking control based on adaptive fuzzy PID algorithm," in Proceedings of the 2019 Chinese Control Conference (CCC), Gangzhou, China, 2019.

[62] A. A. Mohamad, F. H. Kamaru Zaman, and F. A. Ruslan, "Improving steering convergence in autonomous vehicle steering control," Indonesian Journal of Electrical Engineering and Computer Science, vol. 13, no. 1, pp. 279-285, 2019.

[63] E. Vans, G. Vachkov, and A. Sharma, "Vision based autonomous path tracking of a mobile robot using fuzzy logic," in Proceedings of the 2014 Asia-Pacific World Congress on Computer Science and Engineering, Nadi, Fiji, 2014.

[64] J. P. Rastelli and M. S. Peñas, "Fuzzy logic steering control of autonomous vehicles inside roundabouts," Applied Soft Computing, vol. 35, pp. 662-669, 2015.

[65] N. E. Hodge and M. B. Trabia, "Steering fuzzy logic controller for an autonomous vehicle," in Proceedings of the 1999 IEEE International Conference on Robotics and Automation, Detroit, MI, USA, 1999.

[66] C. Zhang, H.-K. Lam, Q. Jianbin, P. Qi, and Q. Chen, "Fuzzymodel-based output feedback steering control in autonomous driving subject to actuator constraints," IEEE Transactions on Fuzzy Systems, p. 1, 2019.

[67] A. M. Zadeh and H. Taghavifar, "A robust fuzzy control approach for path-following control of autonomous vehicles," Soft Computing, vol. 24, no. 5, pp. 3223-3235, 2020.

[68] S. Aminah, B. Mahardika, N. Hanafi, R. S. Dewanto, and D. Pramadihanto, "Control heading on three wheel electric vehicles using fuzzy logic for E-CAK," in Proceedings of the 2019 International Electronics Symposium (IES), Surabaya, Indonesia, 2019.

[69] J. Xu and W. R. Norris, "Hierarchical fuzzy control design and stability analysis for steering-control based vehicles," in Proceedings of the 2019 4th International Conference on Automation, Control and Robotics Engineering, Shenzhen, China, 2019.

[70] M. Abroshan, M. Taiebat, A. Goodarzi, and A. Khajepour, "Automatic steering control in tractor semi-trailer vehicles for low-speed maneuverability enhancement," Proceedings of the Institution of Mechanical Engineers, Part K: Journal of Multi-Body Dynamics, vol. 231, no. 1, pp. 83-102, 2017.

[71] N. Raza, S. Jabbar, J. Han, and K. Han, "Social vehicle-toeverything (V2X) communication model for intelligent transportation systems based on 5G scenario," in Proceedings of the ICFNDS'18, Amman, Jordan, 2018.

[72] A. Pandey, N. Bej, R. Kumar, A. Panda, and D. R. Parhi, "Type-2 fuzzy controller (T2FC) based motion planning of differential-drive pioneer P3-DX wheeled robot in V-REP software platform," in A Journey towards Bio-Inspired Techniques in Software Engineering, pp. 47-57, Springer, Cham, Switzerland, 2020.
[73] X. Xu, P. Su, F. Wang, L. Chen, J. Xie, and V. A. Atindana, "Coordinated control of dual-motor using the interval type-2 fuzzy logic in autonomous steering system of AGV," International Journal of Fuzzy Systems, pp. 1-17, 2020.

[74] X. Wu and W. Li, "Variable steering ratio control of steer-bywire vehicle to improve handling performance," Proceedings of the Institution of Mechanical Engineers, Part D: Journal of Automobile Engineering, vol. 234, no. 2-3, pp. 774-782, 2020.

[75] H. Halin, W. Khairunizam, K. Ikram et al., "Investigation of steering wheel control of an electric buggy car for designing fuzzy controller," in Intelligent Manufacturing \& Mechatronics, pp. 459-468, Springer, Singapore, 2018.

[76] M. Huang, W. Gao, and Z.-P. Jiang, "Connected cruise control with delayed feedback and disturbance: an adaptive dynamic programming approach," International Journal of Adaptive Control and Signal Processing, vol. 33, no. 2, pp. 356-370, 2019.

[77] X. Lu, S. Tang, L. Zhang, P. Li, C. Li, and Y. Wang, "A novel steering control for real autonomous vehicles via PI adaptive dynamic programming," in Proceedings of the 2019 Chinese Control and Decision Conference (CCDC), Nanchang, China, 2019.

[78] Q. Zhu, Z. Huang, D. Liu, and B. Dai, “An adaptive path tracking method for autonomous land vehicle based on neural dynamic programming," in Proceedings of the 2016 IEEE International Conference on Mechatronics and Automation, Harbin, China, 2016.

[79] M. Huang, W. Gao, Y. Wang, and Z.-P. Jiang, "Data-driven shared steering control of semi-autonomous vehicles," IEEE Transactions on Human-Machine Systems, vol. 49, no. 4, pp. 350-361, 2019.

[80] C.-H. Lin and F.-Y. Hsiao, "Proportional-integral sliding mode control with an application in the balance control of a two-wheel vehicle system," Applied Sciences, vol. 10, no. 15, p. 5087, 2020.

[81] P. Wang, S. Gao, L. Li, S. Cheng, and L. Zhao, "Automatic steering control strategy for unmanned vehicles based on robust backstepping sliding mode control theory," IEEE Access, vol. 7, pp. 64984-64992, 2019.

[82] X. He, Y. Liu, C. Lv, X. Ji, and Y. Liu, "Emergency steering control of autonomous vehicle for collision avoidance and stabilisation," Vehicle System Dynamics, vol. 57, no. 8, pp. 1163-1187, 2019.

[83] A. Norouzi, M. Masoumi, A. Barari, and S. Farrokhpour Sani, "Lateral control of an autonomous vehicle using integrated backstepping and sliding mode controller," Proceedings of the Institution of Mechanical Engineers, Part K: Journal of Multi-Body Dynamics, vol. 233, no. 1, pp. 141-151, 2019.

[84] Z. Sun, J. Zheng, Z. Man, M. Fu, and R. Lu, "Nested adaptive super-twisting sliding mode control design for a vehicle steer-by-wire system," Mechanical Systems and Signal Processing, vol. 122, pp. 658-672, 2019.

[85] M. T. M. Emmerich and A. H. Deutz, "A tutorial on multiobjective optimization: fundamentals and evolutionary methods," Natural Computing, vol. 17, no. 3, pp. 585-609, 2018.

[86] S. Son, Y. Jeong, and B. Lee, "A driving decision strategy (DDS) based on machine learning for an autonomous vehicle," in Proceedings of the 2020 International Conference on Information Networking (ICOIN), Barcelona, Spain, 2020.

[87] J. B. Receveur, S. Victor, and P. Melchior, "Autonomous car decision making, and trajectory tracking based on genetic 
algorithms and fractional potential fields," Intelligent Service Robotics, vol. 13, pp. 315-330, 2020.

[88] X. Du, K. K. K. Htet, and K. K. Tan, "Development of a genetic-algorithm-based nonlinear model predictive control scheme on velocity and steering of autonomous vehicles," IEEE Transactions on Industrial Electronics, vol. 63, no. 11, pp. 6970-6977, 2016.

[89] F.-x. Xu, X.-h. Liu, W. Chen, C. Zhou, and B.-w. Cao, "Fractional order PID control for steer-by-wire system of emergency rescue vehicle based on genetic algorithm," Journal of Central South University, vol. 26, no. 9, pp. 2340-2353, 2019.

[90] B. Zhao, H. Wang, Q. Li, J. Li, and Y. Zhao, "PID trajectory tracking control of autonomous ground vehicle based on genetic algorithm," in Proceedings of the 2019 Chinese Control and Decision Conference (CCDC), Nanchang, China, 2019.

[91] J. Guo, Y. Luo, and K. Li, "Robust $H_{\infty}$ fault-tolerant lateral control of four-wheel-steering autonomous vehicles," International Journal of Automotive Technology, vol. 21, no. 4, pp. 993-1000, 2020.

[92] M. A. Khan, M. F. Aftab, E. Ahmed, and I. Youn, "Robust differential steering control system for an independent four wheel drive electric vehicle," International Journal of Automotive Technology, vol. 20, no. 1, pp. 87-97, 2019.

[93] S. Cheng, L. Li, C. Z. Liu, X. Wu, S. N. Fang, and J. W. Yong, "Robust LMI-based H-infinite controller integrating AFS and DYC of autonomous vehicles with parametric uncertainties," IEEE Transactions on Systems, Man, and Cybernetics: Systems, 2020.

[94] P. Hang, X. Chen, and F. Luo, "LPV/ $H_{\infty}$ controller design for path tracking of autonomous ground vehicles through fourwheel steering and direct yaw-moment control," International Journal of Automotive Technology, vol. 20, no. 4, pp. 679-691, 2019.

[95] S. Sharma, G. Tewolde, and J. Kwon, "Lateral and longitudinal motion control of autonomous vehicles using deep learning," in Proceedings of the 2019 IEEE International Conference on Electro Information Technology (EIT), Brookings, SD, USA, 2019.

[96] N. D. Van and G. W. Kim, "Fuzzy logic and deep steering control based recommendation system for self-driving car," in Proceedings of the 2018 18th International Conference on Control, Automation and Systems (ICCAS), PyeongChang, Republic of Korea, 2018.

[97] J. Jhung, I. Bae, J. Moon, T. Kim, J. Kim, and S. Kim, “End-toend steering controller with CNN-based closed-loop feedback for autonomous vehicles," in Proceedings of the 2018 IEEE Intelligent Vehicles Symposium (IV), Suzhou, China, 2018.

[98] W. Yuan, M. Yang, H. Li, C. Wang, and B. Wang, "End-toend learning for high-precision lane keeping via multi-state model," CAAI Transactions on Intelligence Technology, vol. 3, no. 4, pp. 185-190, 2018.

[99] Z. Chen and X. Huang, "End-to-end learning for lane keeping of self-driving cars," in Proceedings of the 2017 IEEE Intelligent Vehicles Symposium (IV), Los Angeles, CA, USA, 2017.

[100] B. Simmons, P. Adwani, H. Pham, Y. Alhuthaifi, and A. Wolek, "Training a remote-control car to autonomously lane-follow using end-to-end neural networks," in Proceedings of the 2019 53rd Annual Conference on Information Sciences and Systems (CISS), Baltimore, MD, USA, 2019.
[101] L. El Hajjami, E. M. Mellouli, and M. Berrada, "Neural network based sliding mode lateral control for autonomous vehicle," in Proceedings of the 2020 1st International Conference on Innovative Research in Applied Science, Engineering and Technology (IRASET), Meknes, Morocco, 2020.

[102] W. Lim, S. Lee, M. Sunwoo, and K. Jo, "Hierarchical trajectory planning of an autonomous car based on the integration of a sampling and an optimization method," IEEE Transactions on Intelligent Transportation Systems, vol. 19, no. 2, pp. 613-626, 2018.

[103] Y. Del Valle, G. K. Venayagamoorthy, S. Mohagheghi, J.-C. Hernandez, R. G. Harley, and Harley, "Particle swarm optimization: basic concepts, variants and applications in power systems," IEEE Transactions on Evolutionary Computation, vol. 12, no. 2, pp. 171-195, 2008.

[104] Y. Rasekhipour, A. Khajepour, S.-K. Chen, and B. Litkouhi, "A potential field-based model predictive path-planning controller for autonomous road vehicles," IEEE Transactions on Intelligent Transportation Systems, vol. 18, no. 5, pp. 1255-1267, 2016.

[105] H. Boumaza, H. Mustapha, and K. Belarbi, "An online solution for model predictive control using particle swarm optimization for autonomous vehicle driving," in Proceedings of the 3rd International Conference on Electromechanical Engineering, Skikda, Algeria, 2018.

[106] X. Wang, X. Yao, and L. Zhang, "Path planning under constraints and path following control of autonomous underwater vehicle with dynamical uncertainties and wave disturbances," Journal of Intelligent \& Robotic Systems, pp. 1-18, 2020.

[107] J. Zhu, Z. Wang, L. Zhang, and D. G. Dorrell, "Braking/ steering coordination control for in-wheel motor drive electric vehicles based on nonlinear model predictive control," Mechanism and Machine Theory, vol. 142, Article ID 103586, 2019.

[108] Z. Zuo, L. Dai, Y. Wang, and X. Yang, "Fast nonlinear model predictive control parallel design using QPSO and its applications on trajectory tracking of autonomous vehicles," in Proceedings of the 2018 13th World Congress on Intelligent Control and Automation (WCICA), Changsha, China, 2018.

[109] M. Z. M. Tumari, A. F. Z. Abidin, M. S. F. Hussin, A. M. A. Kadir, M. S. M. Aras, and M. A. Ahmad, "PSO finetuned model-free PID controller with derivative filter for depth control of hovering autonomous underwater vehicle," in Proceedings of the 10th National Technical Seminar on Underwater System Technology 2018, Gambang, Malaysia, 2019.

[110] A. T. Azar, H. H. Ammar, Z. F. Ibrahim, H. A. Ibrahim, N. A. Mohamed, and M. A. Taha, "Implementation of PID controller with PSO tuning for autonomous vehicle," in Proceedings of the 2019 International Conference on Advanced Intelligent Systems and Informatics, Cairo, Egypt, 2019.

[111] D. H. Kusuma, M. Ali, and N. Sutantra, "The comparison of optimization for active steering control on vehicle using PID controller based on artificial intelligence techniques," in Proceedings of the 2016 International Seminar on Application for Technology of Information and Communication, Semarang, Indonesia, 2016.

[112] A. Al-Mayyahi, W. Wang, and P. Birch, "Path tracking of autonomous ground vehicle based on fractional order PID controller optimized by PSO," in Proceedings of the 2015 IEEE 13th International Symposium on Applied Machine 
Intelligence and Informatics (SAMI), Herl'any, Slovakia, 2015.

[113] N. Radmehr, H. Kharrati, and N. Bayati, "Optimized design of fractional-order PID controllers for autonomous underwater vehicle using genetic algorithm," in Proceedings of the 2015 9th International Conference on Electrical and Electronics Engineering (ELECO), Bursa, Turkey, 2015.

[114] A. Ferrara, G. P. Incremona, and E. Regolin, "Optimizationbased adaptive sliding mode control with application to vehicle dynamics control," International Journal of Robust and Nonlinear Control, vol. 29, no. 3, pp. 550-564, 2019.

[115] R. Alika, E. M. Mellouli, and E. H. Tissir, "Optimization of higher-order sliding mode control parameter using particle swarm optimization for lateral dynamics of autonomous vehicles," in Proceedings of the 2020 1st International Conference on Innovative Research in Applied Science, Engineering and Technology (IRASET), Meknes, Morocco, 2020.

[116] N. H. Amer, H. Zamzuri, K. Hudha, V. Rau Aparow, Z. Abd Kadir, and A. F. Z. Abidin, "Path tracking controller of an autonomous armoured vehicle using modified Stanley controller optimized with particle swarm optimization," Journal of the Brazilian Society of Mechanical Sciences and Engineering, vol. 40, no. 2, p. 104, 2018.

[117] C.-C. Chang, J. Tsai, and S.-J. Pei, "A quantum PSO algorithm for feedback control of semi-autonomous driver assistance systems," in Proceedings of the 2012 12th International Conference on ITS Telecommunications, Taipei, Taiwan, 2012.

[118] S. H. Mousavian and H. R. Koofigar, "Identification-based robust motion control of an AUV: optimized by particle swarm optimization algorithm," Journal of Intelligent \& Robotic Systems, vol. 85, no. 2, pp. 331-352, 2017.

[119] I. Fister, X. S. Yang, I. Fister, J. Brest, and D. Fister, "A brief review of nature-inspired algorithms for optimization," 2013, https://arxiv.org/abs/1307.4186.

[120] A. Biswas, K. K. Mishra, S. Tiwari, and A. K. Misra, "Physicsinspired optimization algorithms: a survey," Journal of Optimization, vol. 2013, Article ID 438152, 16 pages, 2013.

[121] O. K. Erol and I. Eksin, "A new optimization method: big bang-big crunch," Advances in Engineering Software, vol. 37, no. 2, pp. 106-111, 2006.

[122] T. Kumbasar and H. Hagras, "Big bang-big crunch optimization based interval type-2 fuzzy PID cascade controller design strategy," Information Sciences, vol. 282, pp. 277-295, 2014.

[123] Z. W. Geem, J. H. Kim, and G. V. Loganathan, "A new heuristic optimization algorithm: harmony search," Simulation, vol. 76, no. 2, pp. 60-68, 2001.

[124] M. Ahangaran and P. Ramesani, "Harmony search algorithm: strengths and weaknesses," Journal of Computer Engineering and Information Technology, vol. 2, no. 1, 2013.

[125] W. Sun and X. Chang, "An improved harmony search algorithm for power distribution network planning," Journal of Electrical and Computer Engineering, vol. 2015, Article ID 753712, 6 pages, 2015.

[126] K. D. Sharma, A. Chatterjee, and A. Rakshit, "Harmony search-based hybrid stable adaptive fuzzy tracking controllers for vision-based mobile robot navigation," Machine Vision and Applications, vol. 25, no. 2, pp. 405-419, 2014.

[127] Z. He, B. Pan, Z. Liu, and X. Tang, "The mechanical arm control based on harmony search genetic algorithm," Cluster Computing, vol. 20, no. 4, pp. 3251-3261, 2017.
[128] F. Riaz and M. A. Niazi, "Road collisions avoidance using vehicular cyber-physical systems: a taxonomy and review," Complex Adaptive Systems Modeling, vol. 4, no. 1, p. 15, 2016.

[129] M. Kabeer, F. Riaz, M. A. Butt et al., "Emotion enabled cognitive driver," in Proceedings of the 4th International Electrical Engineering Conference, Karachi, Pakistan, 2019.

[130] H. Saleem, R. Khatoon, F. Riaz, and M. A. Butt, "Evaluating the role of neural networks and cyber security for the development of next generation autonomous vehicles: a survey," in Proceedings of the 4th International Electrical Engineering Conference, Karachi, Pakistan, 2019.

[131] M. T. B. A. Lodhi, Y. Mehmood, F. Riaz et al., "Passenger communication system for next-generation self-driving cars: a buddy," International Journal of Advanced Computer Science and Applications, vol. 11, 2020.

[132] M. Kabeer, F. Riaz, S. Jabbar, M. Aloqaily, and S. Abid, "Real world modeling and design of novel simulator for affective computing inspired autonomous vehicle," in Proceedings of the 2019 15th International Wireless Communications \& Mobile Computing Conference (IWCMC), Tangier, Morocco, 2019.

[133] F. Riaz, S. Jabbar, M. Sajid, M. Ahmad, K. Naseer, and N. Ali, "A collision avoidance scheme for autonomous vehicles inspired by human social norms," Computers \& Electrical Engineering, vol. 69, pp. 690-704, 2018.

[134] H. Saied, A. Chemori, M. El Rafei, C. Francis, and F. Pierrot, "From non-model-based to model-based control of PKMS: a comparative study," in Mechanism, Machine, Robotics and Mechatronics Sciences, pp. 153-169, Springer, Cham, Switzerland, 2019.

[135] A. A. Joshi, D. L. Peters, and J. M. Bastiaan, "Autonomous lane change control using proportional-integral-derivative controller and bicycle model (no. 2020-01-0215)," SAE Technical Paper, SAE Publications, Warrendale, PA, USA, 2020. 